\title{
SOBRE MONSTRUOS Y MERCANCÍAS: EL "ESPECTÁCULO" DE LAS BALLENAS EN LA SEGUNDA MITAD DEL SIGLO XIX EN EL SUR DE CHILE
}

\author{
OF MONSTERS AND COMMODITIES: THE “SHOW” OF WHALES IN THE \\ SECOND HALF OF 19TH CENTURY IN THE SOUTHERN CHILE
}

\author{
Daniel Quiroz ${ }^{1}$
}

\begin{abstract}
La ballena ha sido conceptualizada desde el Medioevo con la curiosa dualidad monstruo/recurso, la que se va a mantener en el pensamiento occidental por muchos siglos, sobre todo desde el comienzo de su explotación comercial allá por el siglo X de la era cristiana. En Chile las ballenas eran vistas como "bestias marinas de inmensa grandeza" que en el siglo XVII no eran perseguidas pero las que varaban en sus costas eran muy bien aprovechadas. En el siglo XIX se las comienza a perseguir en forma sistemática para obtener, aceite, barbas, huesos y en muy menor medida, carne. La prensa de la época recoge un rico imaginario que contiene elementos muy diversos: un animal enorme y bravo, por ende monstruoso; heroicos balleneros en una actividad muy peligrosa; una batalla entre hombres y cetáceos; y grandes expectativas sobre la cantidad de dinero que generará la ballena. Pero también está presente el "espectáculo muy animado" que implica la presencia de "muchos curiosos" admirando "la monstruosa ballena". La referencia a "lo espectacular", es decir, la atracción que ejerce la ballena sobre las personas, es un elemento muy frecuente en las noticias publicadas en la prensa.
\end{abstract}

Palabras claves: ballenas, monstruos, caza de ballenas, Chile, narrativas etnográficas.

The whale has been perceived since the Middle Ages through the curious monster/resource duality, which will remain in Western thought for many centuries, especially since the beginning of its commercial exploitation in the 10th century of the Christian era. In Chile whales were seen as "marine beasts of immense grandeur" which were not hunted in the 17h century, even though those that stranded on the shores were very well used. In the 19th century they were systematically captured to obtain oil, baleen plates, bones and, to a lesser extent, meat. The press of the time picks up a rich imaginary that contains diverse elements: an enormous and fierce animal, therefore monstrous; heroic whalers in a very dangerous activity; a battle between men and cetaceans; and great expectations about the amount of money the whale will generate. But there is also the "very animated show" that involves the presence of "many curious onlookers" admiring "the monstrous whale". The reference to "the spectacular", that is, to the attraction that the whale exerts over people, is a very frequent element in the news published in the press.

Key words: Whales, monsters, whaling, Chile, ethnographic narratives.

Lasballenassehan relacionadoconlascomunidades costeras de seres humanos en gran parte del planeta durante un largo tiempo. En la medida que las ballenas se acercaban "a las mismas regiones de las costas del Atlántico y el Pacífico en el curso de sus peregrinajes oceánicos de larga distancia" se transformaron para las personas en "fuente de alimentos y combustible, figuras mitológicas y literarias y, finalmente, en símbolo de la crueldad humana y el peligro ecológico" (Richter 2015:155). La mayoría de los encuentros ocurren en "el

\footnotetext{
${ }^{1}$ Sub Dirección de Investigación, Servicio Nacional del Patrimonio Cultural, Santiago, Chile. daniel.quiroz@patrimoniocultural.gob.cl

Recibido: abril 2019. Aceptado: agosto 2019.
}

http://dx.doi.org/10.4067/S0717-73562020005000401. Publicado en línea: 28-enero-2020. 
espacio litoral", es decir, en ese "lugar interconectado, terrestre y marítimo, situado a ambos lados de la orilla". Los sitios litorales (playas, caletas, zonas de pesca, etc.) "se constituyen material y simbólicamente a través de las interacciones entre los diversos habitantes humanos y no humanos" en dicho espacio, resultado de prácticas pasadas y presentes, "tales como la pesca, la caza de ballenas, la recreación, el tráfico de naves, la construcción de edificios y [también] de narrativas" (Richter 2015:156).

En algunos lugares del planeta "las ballenas son adoradas, respetadas, admiradas, observadas y protegidas", en otros, "son cazadas, sacrificadas, consumidas, comerciadas y temidas", pero incluso a través de esta línea marcada entre conservación y explotación, "hay múltiples manifestaciones comunes, de relaciones tanto físicas como espirituales, entre las personas y el mar, que sugieren un conjunto más sensitivo de actitudes, creencias y prácticas de lo que evidencia el actual debate ballenero" (Parnwell 2014:86), donde unos son "los buenos" y otros "los malos" (Kalland 2009).

Es importante considerar que distintas formas de relacionarse entre humanos y ballenas han existido de manera simultánea, incluso dentro de una misma cultura. Los makah, cazadores ilustres de cetáceos que habitan la costa noroeste de Norteamérica, consideran a las ballenas como un regalo de los dioses: "los humanos son demasiado insignificantes para capturar criaturas tan enormes y poderosas si ellas no desean ser tomadas o no cooperan en su captura" (Miller 2000:184). Los vietnamitas, que no cazan ballenas, si encuentran una muerta en la playa le organizan un funeral y la persona que la encuentra se la considera 'hijo' de la ballena. La ballena es enterrada y después de un tiempo desenterrada y sus huesos, limpios y bendecidos, son colocados en un templo local destinado a las ballenas. En el templo habrá un altar dedicado al genio de la ballena, flanqueado por altares dedicados a otras deidades del mar (Parnwell 2014:87). Los japoneses, que sí las cazan, tienen cementerios que contienen piedras memoriales para honrar a las ballenas muertas con inscripciones que solicitan el renacimiento del espíritu de la ballena como un Budha. Si una comunidad caza sobre un cierto número de ballenas anuales está obligada a construir una tumba conmemorativa que contenga algunos de los huesos de las ballenas y organizar ceremonias para los espíritus de los cetáceos muertos (Kato 2007). Los distintos pueblos, sean makah, vietnamitas o japoneses, muestran respeto por los animales y por sus espíritus, aunque estén en lados opuestos de la línea explotación/ protección (Parnwell 2014:89).

En este marco general de simbolizaciones diversas se insertan las historias que hablan de las ballenas como "monstruos", que forman parte sustantiva del imaginario occidental. Las narraciones vinculadas a un individuo tragado por una ballena son frecuentes, pero no son menos sabidas las historias de aquellas personas que confunden una ballena dormida con una isla y deben escapar cuando se despierta. El relato más conocido de la primera es, sin duda, la historia bíblica del profeta Jonás y sus tres días y tres noches en el vientre de una ballena (Cardona Ramírez 2005) y las narraciones de las extraordinarias peripecias de San Brendan en las aguas del Atlántico Norte reflejan la idea de la ballena como una isla-trampa (Corbella 1991). Muchos de estos relatos ingresan en la tradición occidental transformados en cuentos infantiles como por ejemplo los casos de Pinocho y Simbad. Pinocho encuentra a su padre, Geppeto, en el estómago de un pesce-cane, una criatura "más grande que una casa de cinco pisos, y con un hocico tan grande que pasaría fácilmente todo un tren, los rieles y la locomotora añadida" (Collodi 1983) ${ }^{1}$. Simbad, en su primer viaje, llega a una supuesta isla "que era el lomo de una ballena", la que, mientras descansaba, "tiembla de repente y nos da una gran sacudida [...], los más diligentes se salvaron en la chalupa, los otros se lanzaron a nadar", pero Simbad, "que estaba aún sobre la isla, o mejor dicho sobre la ballena", se toma "de un pedazo de madera que había llevado del barco para hacer fuego" cuando la ballena "se hunde en el mar" (Anónimo 1832:128) (Figura 1).

En la era Cristiana, desde muy temprano, se comienzan a prefigurar diversos significados en torno a las ballenas. En Physiologus, un texto escrito originalmente en griego entre los siglos II y IV AD, se habla de la ballena como "la más grande de todas las bestias que viven en las aguas, cuando nada sobre las olas parece verdaderamente un monstruo; mirándola se piensa que es una montaña en el mar o que se ha formado una isla en medio de las aguas" (Teobaldus 1928:83). Como los navegantes creen que se trata de una isla, al querer descansar después de los rigores de una tempestad, amarran sus naves junto a ella y cuando encienden fuego "el astuto demonio percibe que los hombres están sobre su lomo haciendo su morada, disfrutando del suave clima, entonces, bajo las olas saladas se hunde y arrastra su presa hacia el fondo profundo". La ballena, "huésped del océano, ahoga barcos y hombres en sus aguas, aprisionándolos en los pasillos de la muerte" (Anónimo 1921:17, 21). Estos relatos sobre "monstruosas" ballenas estaban acompañados por otros, no menos relevantes, que mostraban a las ballenas como recursos, siempre disponibles y utilizables. En King's Mirror, un texto escrito en el siglo XIII AD, se asegura que las ballenas, varadas o capturadas, "proporcionan mucha comida para los hombres" (Anónimo 1917:119). Hay algunos cetáceos que no "son comestibles y otros sî", siendo los rorcuales "los mejores de todos como alimento 


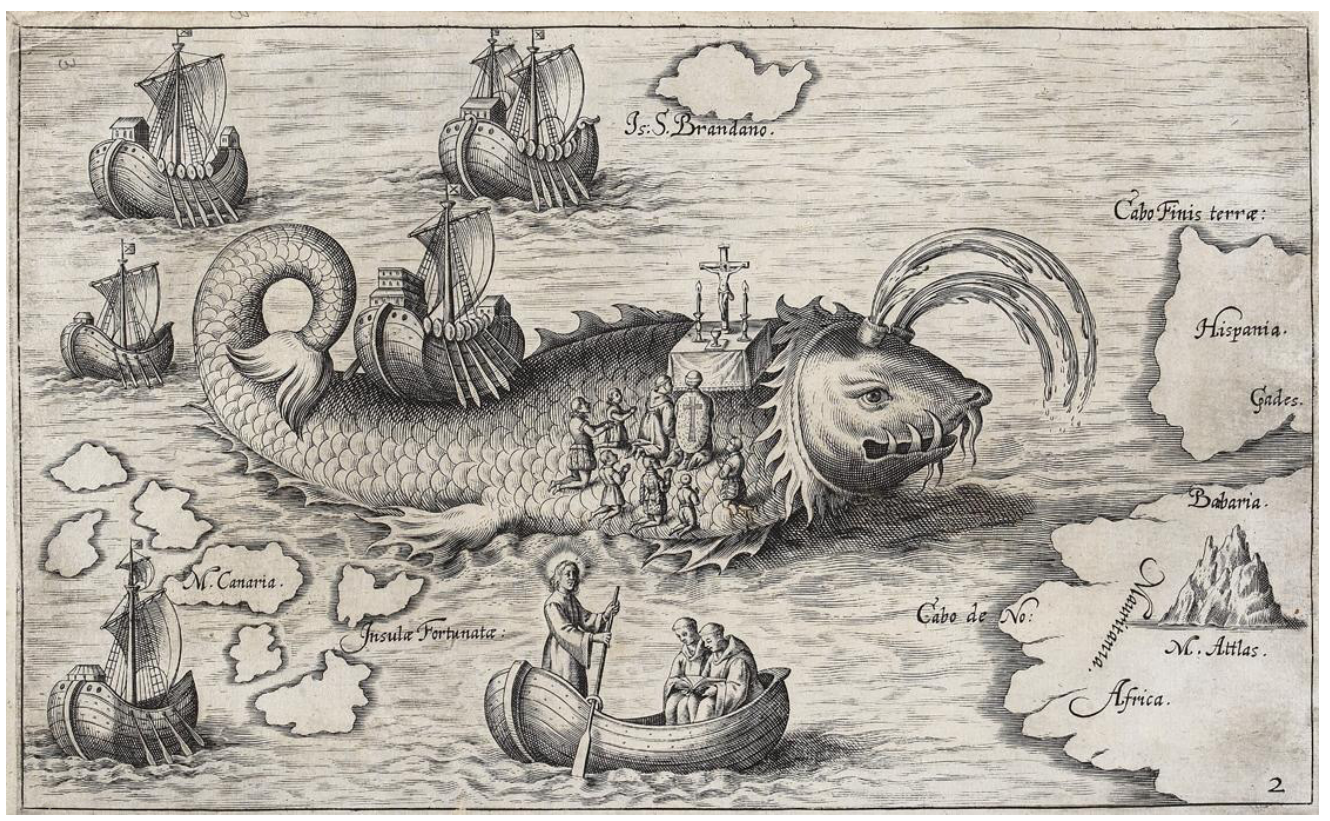

Figura 1. San Brendan sobre el lomo de una ballena. En Honorius Philoponus [Caspar Plautius] Nova typis transacta navigatio novi orbis Indiae Occidentalis, Lynz, 1621. https://archive.org/details/novatypistransac00phil_0, consultado el 30 de octubre de 2017; dominio público.

San Brendan on the back of a whale. In Honorius Philoponus [Caspar Plautius] Nova typis transacta navigatio novi orbis Indiae Occidentalis, Lynz, 1621. https://archive.org/details/novatypistransac00phil_0, accessed October 30, 2017; public domain.

[...], mejor que cualquiera de los otros de los que hemos hablado, aunque se dice que tienen mucha grasa" (Anónimo 1917:124). En el norte de Europa no solamente se cazan ballenas, sino también "se alimentan de ellas" (Anónimo 1917:143).

En términos generales, las ballenas son entendidas como "útiles monstruos de mar" (Vieira 2018:140), tal como fueron descritas por Rocha Pitta en 1730:

es la ballena, estupendo parto de las olas, útil monstruo del mar; tienen las verdaderas setenta palmos de longitud, veintiséis de ancho y dieciocho de alto; siendo pescado, todo su cuerpo es tocino y carne y todas sus espinas son huesos" (Pitta 1730:43-44); agregando que "el amor que este monstruo tiene por sus hijos es también monstruoso, pues por ellos se dejan matar" (Pitta 1730:45).

\section{Perspectivas}

En la "larga historia de interacciones" producida entre las ballenas y los seres humanos, los cetáceos han tenido y tienen, aparte de su valor económico, un significado simbólico muy relevante, no solo entre las culturas más antiguas sino también en las modernas. La mayor parte de los estudios realizados, "proporcionan solo una perspectiva sobre la relación predatoria seres humanos-ballenas, sin reconocer otras formas de interacciones y los mitos, miedos y dogmas sobre las ballenas creados y perpetuados" (Brito et al 2019:15). Karen Oslund señala que la tendencia historiográfica general ha sido separar la historia simbólica de la económica, con el fin de perpetuar una curiosa dicotomía: "ciertas culturas tienen relaciones 'armoniosas', 'naturales' o 'respetuosas' con las ballenas (y por extensión con la naturaleza), mientras que otras se limitan a buscar avances tecnológicos en la caza y 'explotación' de las ballenas" (Oslund 2004:6566). Sin embargo, la historia de la caza de ballenas se puede entender mucho mejor si no está demasiado marcada por la forma como se ha construido una "narrativa maestra contemporánea" donde una larga era pre-occidental de "caza indígena" es seguida por un período de "explotación comercial" llevado por las naciones occidentales, que termina con una época, que aún prevalece, de "protección de la naturaleza", defendida por determinados grupos de interés en los países desarrollados (Oslund 2004:66).

Los antropólogos que han reflexionado sobre las relaciones de los hombres con los animales lo han hecho, en términos generales, de dos modos diversos: considerándolos como "símbolo y/o idea" o bien viéndolos como "alimento y/o mercancía". Vicki Szabo afirma 
que "un animal puede ser bueno para comer y, al mismo tiempo, simbólicamente potente" (Szabo 2008:23). Esta doble noción, monstruo/recurso, se manifiesta en forma muy viva en Europa durante todo el Medioevo, sobre todo desde el momento cuando la ballena comienza a ser explotada comercialmente (siglo X DC).

Las ballenas son "criaturas fronterizas", mamíferos situados en espacios liminales, "entre el agua y el aire, entre el interior y el exterior". Esta naturaleza "limítrofe" [bordering] las hace perfectas "para la interpretación simbólica en muchas sociedades" (Singleton y Lidskog 2018:166). Son seres a la vez "familiares y extraños" y su existencia transcurre "en la frontera entre lo monstruoso y lo mundano"; en el mar son una seria "amenaza para el hombre", pero muertas, en sus costas, son tremendamente "valiosas" (Szabo 2008:30). Las ballenas eran "criaturas de temer y evitar" pero también seres "de enorme valor", por lo que las percepciones sobre los cetáceos "como peligrosos y maliciosos" no podemos separarlas de una preocupación por "su valor y utilidad" (Szabo 2005:1).

Cristina Brito asegura que durante siglos "las monstruosas, enormes, aterradores, varadas, capturadas, útiles, valiosas, extrañas, raras y hermosas ballenas, han provocado [en los seres humanos] tanto atracción como repulsión"; las han observado con "lentes étnicos, culturales, económicos, sociales y científicos, formando una imagen caleidoscópica de ellas" y retratándolas como "una obra divina, una bestia mitológica, un espejo simbólico de rasgos y conductas humanas (principalmente pecados y errores), un presagio de tragedias y catástrofes, un monstruo hecho de grasa y carne para controlar y domesticar" (Brito 2018:2). Las ballenas representan, de alguna manera, las contradicciones propias de los seres humanos (Kalland 2009).

Las ballenas han ejercido, y todavía ejercen, una gran atracción sobre las personas, llevando a hombres, mujeres y niños a las costas "a observar la extraña criatura, a tomar ventaja del recurso, o a ambas". Las ballenas varadas "tienen el poder de evocar miedo y encanto, temor y aprecio, incluso utilidad en forma de grasa, carne, huesos, barbas y dientes [...]; en el siglo XIX también se convertirán en espectáculo, objeto y lugar de entretenimiento" (Brito et al. 2019:22). Son objetos de admiración y se construye todo un show en torno a ellas. El varamiento de una ballena en Ostende, Países Bajos, en 1827, movió multitudes (Bernaert 1829); hoy, en innumerables lugares del planeta, el avistamiento de ballenas es un real espectáculo y ha surgido una verdadera industria que mueve millones de dólares anuales y da empleo a miles de personas (O’Connor et al. 2010).

Independiente de la manera como "la ballena fue o aún es conceptualizada, sea como un rasgo de la divina providencia o un mal presagio, siempre ha sido un elemento de fascinación humana"; la ballena "no solo es un icono desde mediados del siglo XX, con la emergencia de los movimientos conservacionistas globales; lo ha sido siempre" (Brito et al. 2019:25). La "monstruosidad" de la ballena es, sin duda, un símbolo que se ha mantenido hasta nuestros días (Esser-Miles 2014). El tamaño y bravura de la ballena, su "monstruosidad", implica que la tarea de capturarla se considera una verdadera hazaña, convirtiéndose los lugares de caza en memorables campos de batalla, combates recordados y trasmitidos por las comunidades balleneras durante varias generaciones.

Es importante recordar que las ballenas han sido transformadas en Occidente en seres únicos: la "súper ballena", un constructo conceptual que reemplaza el reconocimiento apropiado de las setenta y cinco especies diferentes incluidas en el orden taxonómico de los cetáceos y simplifica y oscurece las actuales circunstancias ecológicas de cada especie de ballena: todas las ballenas están en peligro de extinción y todos los balleneros son unos bárbaros (Kalland 2009:2846). En Occidente existe un discurso dominante, anti ballenero, en el que se ha reemplazado "el ciclo de consumo de las ballenas" de los balleneros por "el ciclo de consumo de la súper ballena", mediante la masificación del turismo, la personificación de la ballena y la generación de un discurso que la describe como una propiedad común, y no como un recurso de acceso abierto (Kalland 2009:135).

Las ballenas han sido "reconstruidas", ya no como recursos que deben ser cosechados, ni especies que deben ser salvadas, sino como individuos que, por exhibir conductas casi humanas, deben ser apreciados y respetados; son animales "con cualidades especiales que lo hacen inherentemente valioso" (Lawrence y Philips 2004:696).

Como se ha señalado recientemente "la palabra 'ballena' es un concepto con muchos significados: un animal, un bien, una creencia, una sorpresa, un presagio, una parte o todos ellos"; la ballena lleva distintas etiquetas "una isla que se mueve, un gran pez, un monstruo marino"; un ser vivo que "es descrito, representado y apropiado de varias formas y en una multitud de maneras". La ballena, que vive en el océano abierto y en los bordes de la costa, "invade constantemente el espacio humano, alternando entre monstruo misterioso, recurso valioso y catalizador de los conflictos humanos" (Brito et al. 2019:24)

\section{Las Ballenas en las Costas de Chile}

El militar español Alonso González de Nájera señala, a fines del siglo XVI, que el mar que baña las costas de Arauco está poblado de "muchas ballenas, las cuáles vi yo no pocas veces de lo alto de los cerros que 
caen sobre él y por sus playas se ve cantidad de huesos de ellas tan grandes que en el castillo de Arauco muchos de ellos, que son de los nudos del espinazo, sirven en las casas de asientos" (González de Nájera 1866:72). Los habitantes de esas costas "hacen coseletes ${ }^{2}$ de barba de ballena que resisten las flechas, formados de tablas de anchura de una mano, cosidas unas con otras, de manera que vienen a ceñir el cuerpo y hacer forma de coraza, aunque no muy ajustadas". También los frenos a sus caballos "los traen de barbas de ballena" (González de Nájera 1866:179, 210).

El historiador jesuita Alonso de Ovalle escribe en 1646 que las ballenas abundan en los mares de Chile y también el ámbar que ellas producen, del que "como los indios no lo conocen, no lo estiman, como tampoco hacían caso de él los araucanos" (Ovalle 1646:43). Diego de Rosales, por su parte, al describir los "anfibios marinos" de Chile en el siglo XVII señala de las ballenas que "no ay aquí quien se ocupe en pescarlas y mucho menos en beneficiarlas" (Rosales 1877, I:39). Del mismo modo, Juan Ignacio Molina, otro jesuita, entrega, en varios de sus textos, fechados entre finales del siglo XVIII y comienzos del XIX, algunos datos sobre la relación entre los mapuches y las ballenas, pero nada dice sobre el uso de los cetáceos. Los "araucanos" llamaban yene "a todas las ballenas de gran corpulencia que distinguen después con varios epítetos adaptados a su forma”. Y al ámbar gris le decían meyene, "es decir estiércol de ballena" (Molina 1788:85, 254).

Alonso de Ovalle nos informa de las varazones de ballenas y de los beneficios que los mapuches sacan de ellas:

No sabemos que estos peces mueran de muerte violenta, porque su disforme grandeza los defiende bien, así del hombre como de otro cualquiera contrario, pero como no están exentas de la común deuda, que pagan todos los vivientes a la muerte, cuando se sienten a cercar a ella se van también acercando a tierra, a donde el mar que no consiente en sí ninguna corrupción las arroja, o muertas o para morir, que es cosa de ver como dan en aquellas costas, y playas midiéndose con ellas aquellos cadáveres de tan inmensa mole, que por más que se ve siempre se admira. Allí mismo se hace el aceite con la fuerza del sol, que derrite su gordura, y cuando el tiempo ha consumido la carne quedan las costillas y demás huesos blancos, de que se aprovechan los indios para hacer algunos bancos, y pudieran hacerse otras muchas curiosidades (Ovalle 1646:43-44).

El historiador jesuita Diego de Rosales nos habla en el siglo XVII de las ballenas en las costas chilenas, definiéndolas como "bestias marinas que son de inmensa grandeza", pues el mar produce "más corpulentos animales [...] que la tierra por las gruesas calidades de sus aguas". Indica que "no hay aquí quien se ocupe en pescarlas y mucho menos en beneficiarlas", excepto "algunos indios chonos y sus confinantes, vecinos al Estrecho de Magallanes", quienes "las comen y se untan todo el cuerpo con su aceite o manteca". Subraya que en Chile "no las persiguen, sino que de las muchas que dan al través en sus costas sacan lo que han menester para su alimento" (Rosales 1877, I:305).

Gonzalez de Agüeros señala que en el archipiélago de Chiloé, a fines del siglo XVIII, hay tantas ballenas que "navegando dos misioneros desde el pueblo de Chonchi para el de Queilén, encontraron tanta multitud de éstas en un Estero o Ensenada, que para evitar el peligro, se vieron obligados a retirarse luego a tierra". Agrega que "muchas de ellas llegan a varar en aquellas costas, porque siguiendo a los pescados y en especial a las sardinas, se entran en las ensenadas en mar lleno, acercándose libremente a las orillas, y cuando quieren retirarse no hayan ya por la vaciante fondo suficiente, y quedan enteramente descubiertas en mar bajo". Los habitantes de estos lugares logran "en estas ocasiones abundancia de aceite, y si es por tiempo de verano, con solo el calor del sol se derrite la grosura, y fácilmente la recogen en las vasijas que tienen destinadas a este fin. Se aprovechan de las barbas, por ser de estimación, y se valen de ellas para embutidos en cajas y otras obras" (Gonzalez de Agüeros 1791:75-76).

Eduard Poeppig, que estuvo en el puerto de Talcahuano en 1828, subraya la abundancia de ballenas en las costas de Chile, notando que son "perseguidas muy poco por los chilenos hasta ahora", de modo que "son tan mansas que se les puede observar nadando sin ninguna preocupación entre los buques anclados en la bahía de Talcahuano". Agrega que son cazadas solo por buques extranjeros, que para hacerlo "tienen que navegar alrededor de la mitad de la tierra"; en cambio, los chilenos, "que pueden alcanzar esas mismas regiones en cuatro a doce semanas", nunca han realizado "la menor tentativa para dedicarse a ella, ni siquiera en las inmediaciones de sus puertos" (Poeppig 1960:314-315) (Figura 2).

La caza costera comercial de ballenas se inicia en la bahía de Concepción en la década de 1830, poco después de la visita de Poeppig. La mayoría de los cronistas indican que en la zona central de Chile no se cazaba ballenas. Aparentemente no ocurría lo mismo en el norte y en el extremo sur. No tenemos relatos sobre los primeros encuentros entre los hombres y las ballenas pero el asombro quedará instalado en la memoria y registrado por sus descendientes y por otros llegados, de muy lejos, mucho tiempo después. Un buen ejemplo son las pinturas rupestres de las costas del norte de Chile que dan cuenta de las complejas relaciones generadas 


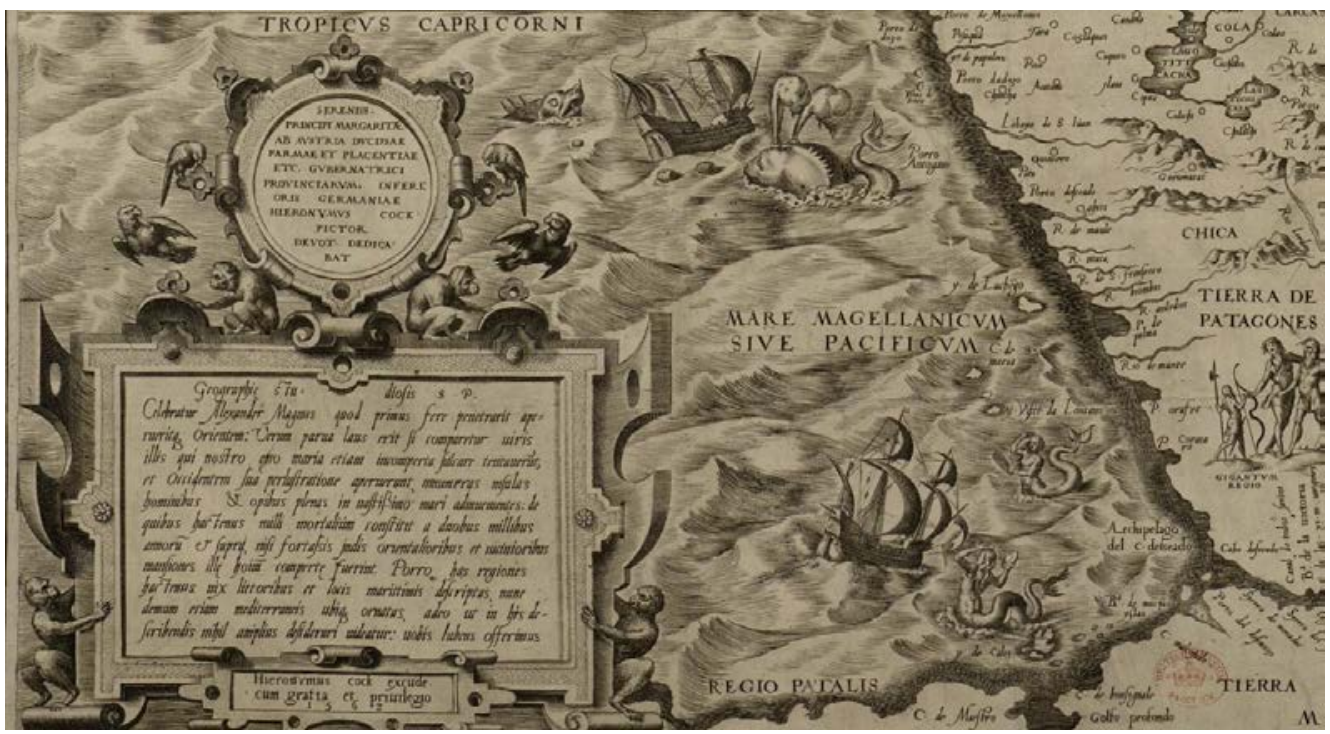

Figura 2. Detalle de la Americae sive quarte orbis partis nova et exactissima, Amberes, 1562, en la que se observan frente a las costas de Chile, ballenas y monstruos marinos. https://www.loc.gov/resource/g3290.ct000342, consultado el 20 de febrero de 2019; dominio público.

Detail of the Americae sive quarte orbis partis nova et exactissima, Antwerp, 1562, in which whales and sea monsters off the coast of Chile are observed. https://www.loc.gov/resource/g3290.ct000342, accessed February 20, 2019; public domain.

entre hombres y cetáceos. Las pinturas de El Médano y las otras descubiertas en sus cercanías, son un reflejo de la importancia concedida a las ballenas por los grupos de pescadores que ocupaban estas costas (Ballester 2018). ¿Los grupos que pintaron en las paredes de la quebrada de El Médano y en otros lugares cazaron ballenas? Es un tema discutible y hemos escuchado las razones de los que responden afirmativamente y también de los que manifiestan algún grado de escepticismo. Se ha querido ver en las pinturas de El Médano "escenas de caza", pero pueden corresponder al remolque de cetáceos varados y no a la captura de animales sanos y libres. Podemos comparar lo representado en las pinturas rupestres con la descripción que hace el antropólogo alemán Martín Gusinde de la posible caza de ballenas entre los grupos canoeros del extremo sur americano. Gusinde cree que los grupos canoeros del extremo sur americano no cazaban ballenas; sin embargo, cuando veían una ballena acosada o herida, se acercaban en sus canoas desde todas direcciones, "los hombres lanzan sus largos arpones y todos tiran violentamente de las cuerdas para hacer mayores las muchas y graves heridas del animal. Es atacado por todos lados, hasta que, al fin, cada hombre le arroja todas las armas que tiene a mano". $\mathrm{Si}$ consiguen dar muerte al animal "entonces arrastran la enorme presa a la playa aprovechándose de la marea con cuyo auxilio empujan el deforme cuerpo del animal lo más alto que pueden tierra adentro" (Gusinde 1951:212-213). Es una descripción que podría aplicarse a las pinturas de El Médano, donde la canoa reemplaza a la balsa de cuero de lobo.

Aunque no cazaran ballenas, el provecho que los pueblos originarios hacían de las carcasas de los cetáceos es indesmentible. Los utensilios en huesos de ballena que emergen en los trabajos arqueológicos realizados en los sitios de la costa chilena son un buen marcador de la importancia de esta materia prima para los grupos que la poblaron desde hace miles de años. El ñirewe, que se encuentra aún vigente en las comunidades mapuche del centro sur de Chile, es uno de los ejemplos más característicos. También su uso en la confección de textiles. Pero no sólo tenemos estos apretadores sino también aparecen diversos tipos de torteras utilizadas para la elaboración de los hilos con los que se fabricarán los tejidos. Había también "palas", "azadas", "cuñas", "machetes", "flotadores", todos ellos elaborados en hueso de ballena. No tenemos ningún dato que nos permita suponer que estas poblaciones cazaron ballenas en sus dominios. Incluso tampoco sabemos si se beneficiaban de su grasa y carne, probablemente no lo hicieron. Las poblaciones del extremo sur americano también elaboraron diversos utensilios en huesos de ballena: las puntas de arpón para cazar lobos marinos y las cuñas para desprender la corteza de los árboles son muy frecuentes y todavía se usaban cuando los europeos llegaron y se asentaron en esas costas. Sabemos, además, que no sólo los huesos eran utilizados por estos grupos para elaborar utensilios. También las barbas de las ballenas servían para 
unir partes de objetos complejos, como cajas de madera y recipientes de corteza. Pero no solamente los huesos. También la grasa y la carne de los cetáceos era un recurso en extremo valioso para las poblaciones que vivían en las costas de Chile, sobre todo para aquellos grupos que vivían en el extremo sur del continente americano. Sabemos que se congregaban frente a una ballena varada y se la repartían según códigos y costumbres no muy conocidas. Los europeos se manifestaron asombrados de la importancia que le otorgaban los pueblos fueguinos a estos eventos, que ocurrían de manera frecuente en sus costas. Las ballenas son mencionadas en la literatura sobre los grupos fuego-patagónicos como un suministro importante de grandes cantidades de comida y grasa y como fuente relevante de materias primas. La noticia de la presencia de una ballena lograba que se viajara desde lugares muy lejanos para compartir todos sus productos. Con un solo ejemplar "se abastece a muchas familias durante varias semanas; su carne y aceite, huesos y tendones, barbas y dientes tienen un útil y variado aprovechamiento" (Gusinde 1951:212-213). Disponer de una ballena no solo era "tener abundancia de alimentos", sino también "era signo de riqueza" y en ese sentido, para los yaganes, "la ballena era el alimento más importante" (Swensen, 2014:74). Para los canoeros del extremo sur americano, la varazón de una ballena era "un gran regalo de la naturaleza" (Chapman 2012:81).

Durante la primera mitad del siglo XIX la caza comercial de ballenas se instala en la zona del Golfo de Concepción. En el Censo General de Población de la República de Chile de 1854 aparecen registrados en Tumbes, San Vicente y Talcahuano 30 balleneros, 28 chilenos y dos extranjeros ${ }^{3}$. Los balleneros comienzan a ocupar en forma paulatina durante las últimas décadas del siglo XIX "todo el litoral del centro sur de Chile" (Quiroz 2016). Lebu se constituye en el extremo meridional de una extensa zona de captura ocupada por pescadores de Talcahuano, tal como se establece en los permisos otorgados por las autoridades de la zona para la pesca de ballenas ${ }^{4}$. La autorización otorgada en 1869 a José Olivares, de Tumbes, para "salir a la pesca de ballenas en embarcaciones menores", delimitaba claramente un territorio de pesca en la segunda mitad del siglo XIX, que estaba comprendido por "la isla Santa María, costa de Arauco i Lebu"5. A fines de ese siglo la zona de captura se ampliará a Valdivia y más tarde a Maullín y Chiloé (Castillo 1907; Quiroz 2016). En Punta Arenas no se registra pesca costera de ballenas en esa época, aunque el aprovechamiento de animales varados era una práctica común entre los magallánicos, no solo de los grupos originarios (Quiroz et al. 2016) sino también de los descendientes de europeos que se radicaron en la zona desde fines del siglo XIX. Los documentos que analizaremos provienen principalmente de esta época y este territorio.
La primera década del siglo XX trae la llegada al país de la caza moderna de ballenas, con buques a vapor equipados con un cañón arponero y el establecimiento de plantas balleneras en Punta Arenas y Valdivia. En 1903 se realiza un interesante experimento, impulsado por el capitán noruego Adolf Andresen y el empresario magallánico Mauricio Braun, para capturar cetáceos en el sur de Chile con el sistema moderno de caza de ballenas practicado en el norte de Europa. En este experimento se capturan cuatro ballenas. A pesar de lo exiguo que puede parecer esta cifra, permitió amortizar el costo del experimento, probar la eficiencia del cañón arponero, y que finalmente, se decidiera dar inicio a un emprendimiento a mayor escala (Quiroz y Mayorga 2018). Se trata de la Sociedad Ballenera de Magallanes, compañía que operará entre 1905 y 1913 capturando en los canales patagónicos y aguas de la Antártica cerca de 4.000 ballenas, con un promedio de 445 ballenas/año (Quiroz 2011). Esta iniciativa fue desarrollada aprovechando los conocimientos que la industria ballenera noruega había acumulado durante sus actividades en los mares del norte. Los noruegos se hacen cargo, además, de un conjunto de operaciones balleneras tanto en Valdivia como en Chiloé, modernizando sus instalaciones y el equipamiento necesario para desarrollarlas (Quiroz y Pastene 2014). En Chile se continuará cazando ballenas con este sistema hasta 1983 (Pastene y Quiroz 2010).

Estas nuevas "máquinas" y "maquinarias" contribuirán a transformar la visión que las poblaciones costeras tienen de las ballenas (Quiroz y Carreño 2017), pero es un tema que no analizaremos en el contexto de este trabajo.

\section{Documentos}

En este trabajo queremos examinar cómo se representa esta "doble naturaleza" de las ballenas, monstruo/recurso (Quiroz y Carreño 2017), en la prensa de Concepción, Lebu y Punta Arenas durante la segunda mitad del siglo XIX y primera década del siglo XX. Estos son lugares específicos donde la caza y/o procesamiento de cetáceos fue una práctica común y muy reconocida por las comunidades locales. El recurso a los periódicos es importante porque son un lugar adecuado donde encontrar referencias sobre el uso que las personas hacen de ciertas ideas sobre las ballenas y su caza en una determinada época.

Los medios de comunicación masiva, como la prensa, son una de las vías que se usa para dar a conocer las representaciones sociales. Los periódicos "no solo transmiten información, sino reflexiones" (Cuevas 2011:10). La prensa normalmente publica una "esquematización", es decir "fragmentos de mundo o micro universos" (Miéville 1986:120), que se 
constituyen finalmente en la representación social de un evento cualquiera. Un esquema es "una representación discursiva orientada a un destinatario, sobre aquello que su autor concibe o imagina de una cierta realidad, y tiene como fin hacer que el destinatario comparta dicha concepción (Grize 1996:50). La esquematización está compuesta de una serie de imágenes, las que pueden, en principio, "describirse sobre la base de configuraciones discursivas" o argumentos (Gutiérrez 2006:242). Es necesario recordar que la prensa "es una fuente documental, no como fuente objetiva, sino como un lugar de argumentación de diferentes representaciones sociales"; además, la prensa tiene "una gran importancia en la sociedad, ya que la presentación de noticias y columnas es una construcción social: los medios, en su proceso de informar, elaboran y proyectan representaciones sociales y son una fuente de consulta" (Cuevas 2011:16). Como señala Bruno Latour, muchas de las notas de los periódicos son textos híbridos, "que dibujan madejas de ciencia, de política, de economía, derecho, técnica y ficción [...]; la cultura y la naturaleza se mezclan todos los días" (Latour 1993:17).

Hemos revisado la prensa de Concepción, Lebu y Punta Arenas correspondiente a la segunda mitad del siglo XIX y primera década del siglo XX [18521910] en la Biblioteca Nacional de Chile 6 , buscando datos sobre las representaciones de las relaciones entre hombres y ballenas en esa época.

El tipo de relato más abundante que aparece es lo que podemos llamar "noticia", es decir, un texto breve que habla sobre algún acontecimiento ocurrido hace poco tiempo, ayer, un par de días atrás. Entre las noticias sobre la relación entre hombres y ballenas escogimos solo aquellas que mencionaran ballenas "depositadas" en las playas, producto de la caza o por un varamiento ${ }^{7}$ o bien ballenas "avistadas" desde la costa. Obtuvimos un corpus de 44 "noticias" distribuidas entre los años 1862 y 1904.

La prensa publica, además de las noticias, algunos textos más extensos con reflexiones sobre la pesca costera de ballenas, incluyendo interesantes datos sobre "monstruos y héroes", sobre ballenas y balleneros. Entre estos textos se destaca un largo reportaje sobre "la pesca de ballenas" en caleta Tumbes, bahía de Concepción, escrito por Diego Dublé Urrutia y publicado a comienzos de 1905 en el diario El Sur de Concepción ${ }^{8}$. De dicho reportaje hemos recortado seis párrafos que nos ilustran de buena manera la mirada del escritor, que recoge indudablemente el sentir de la comunidad local, de los "penquistas", sobre las ballenas y la caza de los cetáceos. Cada una de estas referencias son nuestros "recortes" (Quiroz 2016), es decir, contamos con un corpus de 50 piezas encontradas en la revisión de los periódicos. En estos recortes esperamos encontrar algunas respuestas que nos ilustren sobre la presencia de esta visión dual de las ballenas como monstruos/ mercancías en las costas de Chile y su naturaleza heroica/espectacular a fines del siglo XIX.

Utilizamos una secuencia de siete ilustraciones como un para-texto que busca complementar el texto escrito. Desafortunadamente no encontramos imágenes en los periódicos que revisamos, excepto la Figura 6, por lo que la mayoría de ellas es de procedencia extranjera.

\section{EI Problema}

En el periódico El Correo del Sur de Concepción se publica en 1862 una breve noticia sobre las peripecias de un grupo de pescadores intentando capturar "la reina de las ballenas":

Hará como unos doce días que en la bahía de San Vicente apareció una que, según dicen, puede llamarse con justicia la reina de las ballenas por su tamaño i bravura. Al fin, después de arriesgar su pellejo sus perseguidores durante una semana para dar caza al monstruo marino que burlaba sus pesquisas, cuando iban a darle el golpe mortal lograron atraparlo i colocarlo a poca distancia de la playa. Pero, a lo que parece, el trabajo se ha perdido del todo: la ballena después de desangrar no ha flotado, como sucede siempre, sobre la superficie del mar, a pesar de haber transcurrido a la fecha mucho más del tiempo necesario. El chasco sería grande i sin ejemplo para los pobres pescadores sino boya la ballena, pues han contraído fuertes compromisos que esperan satisfacer con el producto de la venta del aceite.

En este texto se destaca no solamente la idea de la ballena como un "monstruo marino" que sistemáticamente "burlaba sus pesquisas", sino también se registra la batalla entre los pescadores y el cetáceo, destacando la naturaleza heroica de los balleneros, dispuestos a "arriesgar su pellejo" para perseguirlo durante toda una semana, y la bravura de la ballena, sin olvidar las utilidades que debe significar su captura y procesamiento, pues "han contraído fuertes compromisos que esperan satisfacer con el producto de la venta del aceite".

Estas "ideas fuerza" nuevamente aparecen en otra noticia publicada un año después en el mismo periódico:

Este lugar de la playa [de Tumbes] ofrecía ayer un espectáculo mui animado, habiéndose presentado muchos curiosos para admirar la monstruosa ballena cazada por el animoso pescador Olivares, quién se halló en esta ocasión expuesto a un grave peligro a consecuencia de una colada recia de la ballena, que arrojando 
sobre la tripulación del bote una fuerte marejada tiró al jefe de ella al agua i casi hizo ir de pique la embarcación misma. Según testigos fidedignos el enorme pez medía en efecto $32 \frac{1}{2} 2$ varas de largo i es por consiguiente uno de los mayores de la especie que jamás se han presentado en estos lugares; pero habiéndose encontrado demasiado flaco, se calcula producirá mucho menor cantidad de aceite de la que debía esperarse por su tamaño"10.

Finalmente, nos gustaría agregar una última noticia y así configurar de una manera más completa el problema:

Una hermosa ballena se le antojó [...hace] días, venir a dar un paseo por nuestra bahía; tan pronto una compañía de balleneros tuvo noticia de esta ocurrencia, mandó algunos botes bien armados en su persecución; Sin embargo, [a pesar] de haberle clavado un arpón, no pudieron darle caza $^{11}$.

Tenemos una ballena brava y monstruosa, hermosa en su "monstruosidad", heroicos balleneros en una actividad muy peligrosa, la representación de la dura batalla que se produce entre hombres y cetáceos y grandes expectativas sobre la cantidad de aceite que generará la ballena. Lo novedoso es la alusión al "espectáculo muy animado" que implica la presencia de "muchos curiosos" admirando "la monstruosa ballena" capturada por el "animoso pescador Olivares". La idea de espectáculo, la atracción que ejerce una ballena sobre la gente, es una característica muy frecuente en las noticias publicadas en la prensa. No podemos dejar de pensar en la frase que lanza Dublé Urrutia al hablar de los pescadores de Tumbes: "después de algunos días entra la ballena a Tumbes entre el general entusiasmo de la gente; largo seria describir este acto triunfal que recuerda la entrada a Roma de los cónsules de República, seguidos por algún rey o reina bárbaro, encadenado" 12 .

Estos cuatro conceptos, monstruos/mercancías, batallas/espectáculos, son los elementos centrales de la esquematización que forma el micro universo de los discursos construidos entre los pobladores de las costas del sur de Chile durante gran parte del siglo XIX y comienzos del XX y representados en la prensa sobre la compleja relación entre los hombres y las ballenas.

\section{La Ballena como Monstruo}

Uno de los aspectos más recurrentes en los recortes revisados es el término "monstruo" incorporado en la descripción de la ballena. Se habla de "monstruo marino"13, de "horrible monstruo"14, de "monstruo de los mares" $" 15$ de "monstruosa ballena"16, aunque aparecen también términos más benévolos como, por ejemplo, "una hermosa ballena"17. Una frase muy sugerente es aquella que implica el reconocimiento de un ejemplar como la "reina de las ballenas, por su tamaño y bravura"18. Un aspecto relevante de la "monstruosidad" de la ballena es, por supuesto, su gran tamaño. Pero no solo el tamaño sino también la bravura y peligrosidad de la ballena son parte importante de su monstruosidad.

Se habla de una "gran ballena"19, de una "ballena enorme" ${ }^{20}$, de un "enorme pez" ${ }^{21}$ que se había estimado de "cuarenta varas de largo",22, pero que "medía en efecto $321 / 2 \operatorname{varas}^{23}$ de largo" 24 y, de un cetáceo "enormemente grande" 25 , de una ballena "de grandes proporciones" 26 , "de grandes dimensiones"27 "de enormes dimensiones" 28 , en fin, de "un enorme cetáceo" 29 y nuevamente de una "gran ballena" ". Una de las ballenas remolcadas en 1888 a San Vicente medía unos " 23 metros de largo por 5 de circunferencia" ${ }^{\prime \prime}$.

Las cuatro ballenas reportadas en Lebu, en cambio, no son grandes, sino, al contrario, de tamaño reducido. Es así como se habla de un ballenato de "17 varas de largo" 32 , algo más de 14 metros, y que el resto son aún menores, "una pequeña ballena" 33 , otra cuyo porte "es chico"34 y finalmente otra "pequeña"

Las ballenas observadas en Punta Arenas son todas de un gran tamaño y los adjetivos se repiten: "una enorme y colosal ballena" y "un cachalote excepcional", de "enormes dimensiones"36; también de una "gigantesca ballena"37. Incluso se cuenta que una ballena encontrada en isla Navarino, al sur del canal Beagle, "por sus proporciones colosales merece ser considerada entre los más grandes ejemplares de ese cetáceo que se hayan visto en estos mares, pues medía 38 metros de largo" "38.

El gran tamaño de la ballena se trasmite obviamente a sus restos. Diego Dublé Urrutia, en su reportaje sobre caleta Tumbes, señala que la ballena es un "monstruo cuyas enormes costillas, quijadas y paletillas, blanquean por todas partes, dando firmeza a los caminos" y "enormes vertebras de este cetáceo sirven de asiento a los pescadores"39.

Estas descripciones de "enormes ballenas", ¿corresponden a ejemplares de especies "reales" o bien son una manera de hablar de lo que ellas representan? (Figura 3).

La información disponible nos indica que la especie cazada por los pescadores costeros de Tumbes, San Vicente y Lebu era la ballena franca austral (Eubalaena australis Desmoulins 1822) ${ }^{40}$, conocida como "raituel" o "reituel", palabras derivadas de right whale, su nombre en inglés (Castillo 1906; Clarke 1965). La ballena franca austral tiene una longitud aproximada de 15 metros y un peso de 50 toneladas (Branch et al. 2010). Especímenes con más de 20 metros deben ser, sin duda, considerados ejemplares de gran tamaño o simplemente corresponder a otra especie de ballena. Sin embargo, los ejemplares 


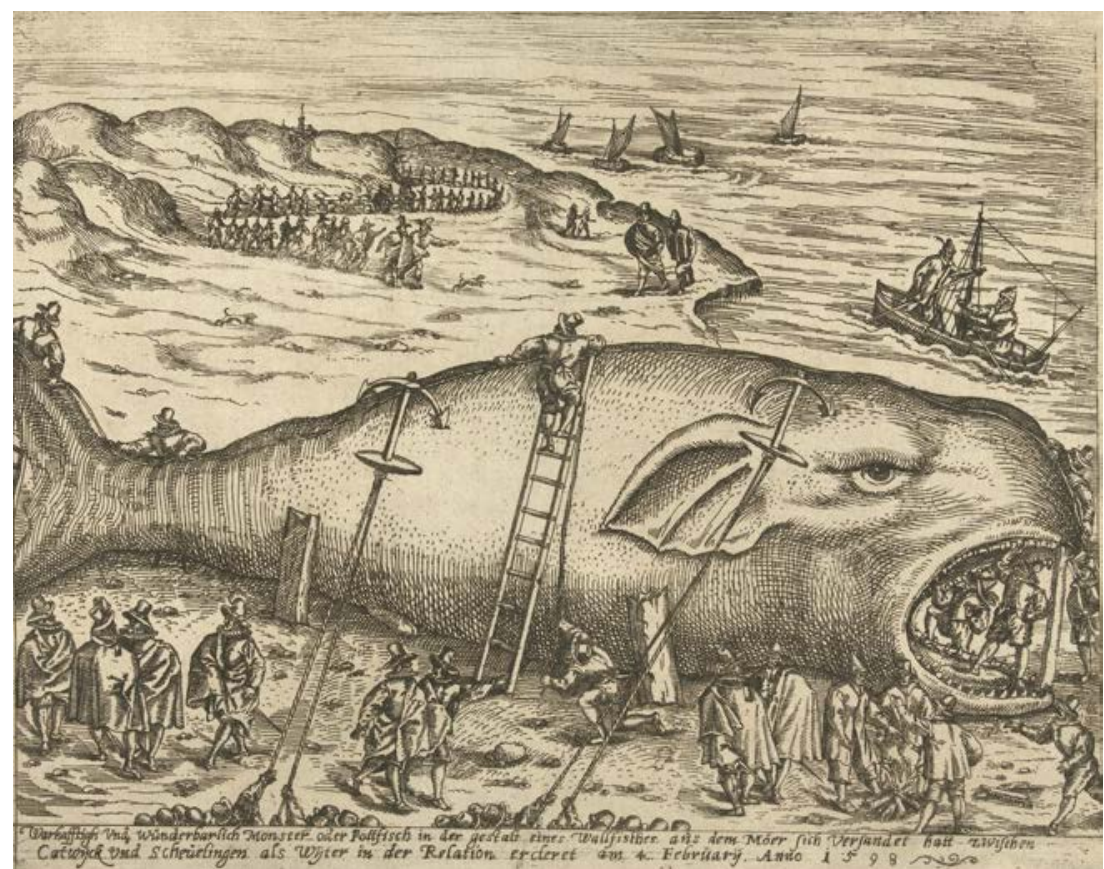

Figura 3. "Maravilloso monstruo con forma de ballena", varado en Katwijk aan Zee, Paises Bajos, 1598. Jacobus Francus, Historicae Relationis Continvato. Warhafftige Beschreibunge aller gedenckwürdiger Historien. Frankfurt: N. Heinrich, 1598; http://www.europeana.eu/portal/en/record/9200332/ BibliographicResource_3000149250265.html consultado el 30 de septiembre de 2017; dominio público.

"Wonderful whale-shaped monster", stranded in Katwijk aan Zee, Netherlands, 1598. In Jacobus Francus, Historicae Relationis Continvato. Warhafftige Beschreibunge aller gedenckwürdiger Historien. Frankfurt: N. Heinrich, 1598; http://www.europeana.eu/portal/en/record/9200332/BibliographicResource_3000149250265. html accessed September 30, 2017; public domain.

varados pueden corresponder a especies de ballenas más grandes como la de aleta (Balaenoptera physalus Linnaeus 1758) o la azul (Balaenoptera musculus Linnaeus 1758), que puede alcanzar los 30 metros de largo.

\section{La Ballena como Mercancía}

La ballena era considerada no solo un monstruo sino también un recurso en el que se depositaban muchas esperanzas. Para equiparse con lo necesario para la caza de ballenas, los balleneros "contraen grandes compromisos que esperan satisfacer con el producto de la venta del aceite" $"$;1 para ellos cada cetáceo capturado "les promete un muy buen lucro"42 pero, a veces, las expectativas no se ven satisfechas pues el ejemplar resulta "demasiado flaco" y produce "mucha menor cantidad de aceite" que la esperada ${ }^{43}$.

Varios recortes se enfocan en la cantidad de aceite que produce una ballena y en el dinero obtenido con su venta. Respecto de la cantidad de aceite tenemos datos en cinco casos ocurridos entre 1885 y 1898. En el primero la ballena produce "unos 30 barriles" "veinte barricas de aceite, de cuarenta galones cada una" ${ }^{\prime 4}$, en el tercero "novecientos galones de aceite" ${ }^{\prime 6}$, en el cuarto tenemos que genera "80 barriles" o 2.400 galones $^{47}$ y en el último, "3.068 galones"48 (Figura 4).

Las unidades de medida utilizadas en las noticias son barricas, barriles, galones, pero las equivalencias entregadas son algo contradictorias. Por ejemplo, se indica que "una barrica" son cuarenta galones y "un barril" tendría treinta galones. La equivalencia internacional más usada indica que un barril de aceite corresponde a 42 galones y a 159 litros de aceite, pero es preciso señalar que los sistemas de medidas no estaban muy estandarizados en el siglo XIX (Coleman 1995). Dublé Urrutia (1905b) indica que un barril de aceite son 30 galones. Podemos tratar de reducir todas las medidas a galones, respetando las equivalencias indicadas en los textos: la primera ballena genera 1.260 galones $^{49}$, la segunda 800 galone $^{50}$, la tercera 900 galones, la cuarta 2.400 galones y la última 3.068 galones. Estas cifras nos darían un promedio de 1686 galones de aceite por ballena. Los precios de venta del aceite también son variables: el aceite de la cuarta ballena se vende a 80 centavos el galón ${ }^{51}$ y el de la quinta a un peso el galón ${ }^{52}$, lo que da $\$ 1.960$ en un caso $^{53}$ y $\$ 3.068$ en el otro ${ }^{54}$.

Tenemos también algunas referencias sobre "la productividad" de las ballenas en las noticias de Lebu en 


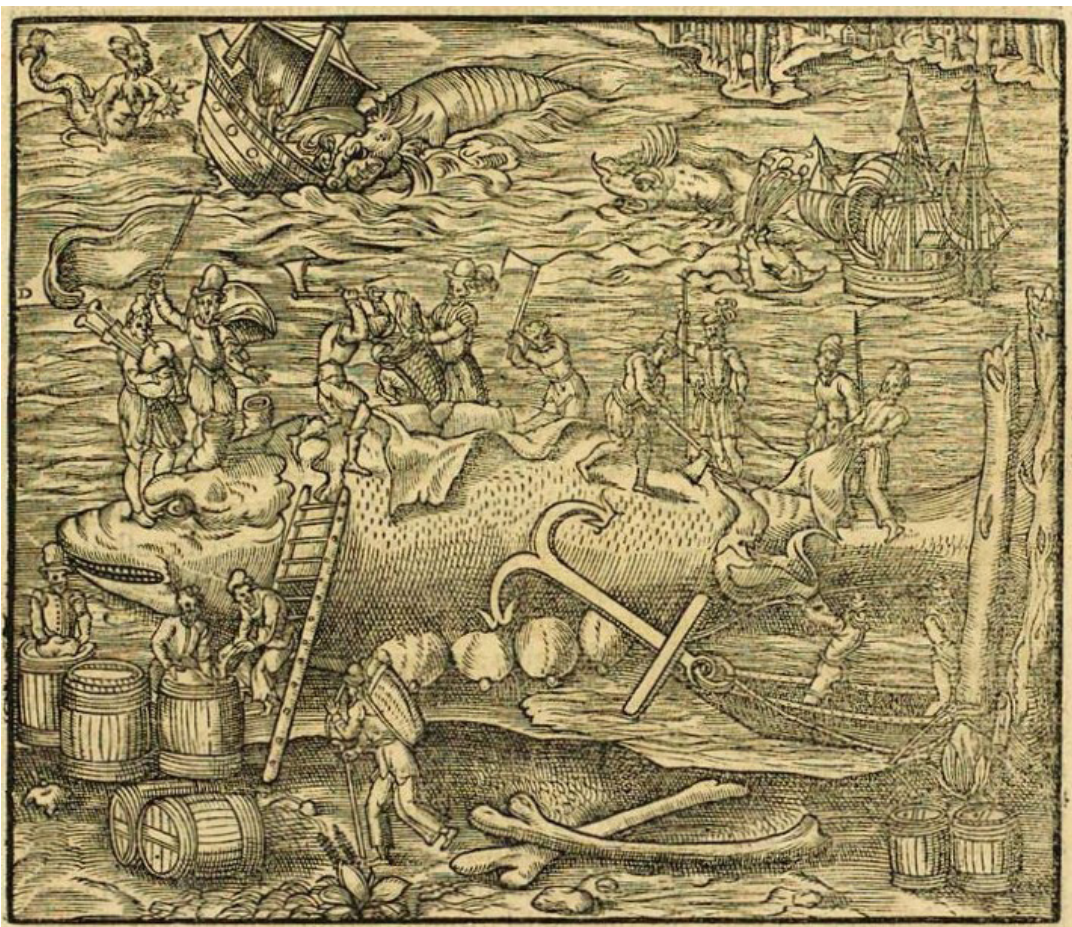

Figura 4. El procesamiento de una ballena, 1575. Andre Thevet, Cosmographie Universelle, Tomo II. Paris: Guillaume Chaudier, 1575; http://objdigital.bn.br/objdigital2/acervo_digital/div_obrasraras/ or815981/or815981.pdf, consultado el 30 de noviembre de 2018; dominio público.

The processing of a whale, 1575. Andre Thevet, Cosmographie Universelle, Volume II. Paris: Guillaume Chaudier, 1575; http://objdigital.bn.br/objdigital2/acervo_digital/div_obrasraras/or815981/or815981.pdf, accessed November 30, 2018; public domain.

1890. Se informa primero que se pescó una ballena de " 17 varas de largo y [que] producirá, según los interesados, unos dos mil pesos" "־5, luego otra cuyo tamaño "es chico y su producido alcanzará, según se nos ha dicho, a mil y tantos pesos" ${ }^{" 56}$ y finalmente una todavía más "pequeña, que dará 700 pesos más o menos ${ }^{57}$. Si suponemos un valor de 80 centavos el galón tendríamos que la primera habría producido 2.500 barriles, la segunda 1.500 barriles (si es que "mil y tantos" son 1.200 pesos) y la tercera 875 barriles, con un promedio de 1.625 galones por ballena.

Los valores se modifican en el tiempo. En 1905 el galón de aceite de ballena se vendía en Tumbes a \$0,40. Una ballena "mediana rinde 40 barriles de aceite", o "1.200 galones", considerando barriles de 30 y no de 42 galones (Dublé Urrrutia 1905b). Es decir, cada ballena rendiría unos $\$ 480$ en aceite.

Se registran muchas decepciones. Un ejemplar de buen "porte", se encontraba "demasiado flaco", por lo que "producirá mucho menor cantidad de aceite de la que debía esperarse por su tamaño"s8.

La ballena produce principalmente aceite, pero también las barbas constituyen un recurso codiciado, aunque durante muchos años no "se conseguía pescar ballenas cuyas barbas pudieran utilizarse en el comercio"s9. En 1898 se lograron capturar dos ballenas que permitieron comercializar sus barbas, una por pescadores de San Vicente y la otra por los Olivares de Tumbes ${ }^{60}$. La ballena de San Vicente generó $\$ 600^{61}$ en barbas y la de Tumbes $\$ 3.034,90^{62}$. Si consideramos que el precio era de $\$ 4,5$ la libra de barbas ${ }^{63}$, tenemos que hay una gran diferencia entre lo que produjo una, 135 libras, y la otra, 750 libras. El quintal ${ }^{64}$ de barbas de ballena en Tumbes se vendía en 1905 a \$ 600 (Dublé Urrutia 1905b), es decir a \$ 6 la libra.

Los recortes nos hablan también de algunos compradores locales de aceite, como David Fuentes ${ }^{65}$ y Juan Alemparte ${ }^{66}$, y de barbas, como Horman \& $\mathrm{Cia}^{67}$, a fines del siglo XIX.

Una breve "fuga monetaria". Una ballena franca cazada en 1896 por los Olivares, dueños de la estación ballenera de Tumbes produce un total de $\$ 6.102,90$, con 3.068 galones de aceite a $\$ 1$ el galón y 749,35 libras de barbas a $\$ 4,5$ la libra ${ }^{68}$. ¿Cuántos pesos de 2018 son $\$ 6.103$ de 1896 ? Sabemos que 1 US $\$$ de 1896 corresponde a $\$ 2,84$ de ese mismo año (Braun et al 2000: 117), por lo que $\$ 6.103$ son US $\$ 2.149$ de 1896 . Sabemos también que 1 US\$ de 1896 corresponde a US\$30,46 de $2018^{69}$, por lo que $\$ 6.103$ de 1896 son US $\$ 65.457$ de 2018, es decir $\$ 45.537 .658$, si consideramos que 1 US $\$$ de 2018 equivale a $\$ 695,69^{70}$. Es decir una ballena podría generar unos 45,5 millones de pesos actuales. Una cifra bastante significativa. 
Es importante señalar que no solo "la ballena cazada" es considerada una mercancía; también lo es "la ballena varada". En la Gobernación Marítima de Magallanes "se ha presentado el señor Wilfred Garnett exponiendo que ha encontrado en Bahía Lomax, hará 20 días una ballena de 30 metros de largo en buen estado y deseando beneficiarla como dueño o primer ocupante, hace en consecuencia la denuncia correspondiente para los fines del caso" "71. No sabemos que ocurrió con esa ballena, pero sí tenemos información muy completa sobre otra que fue beneficiada en isla Navarino, que le "ha dado a su dueño, don Fortunato Bevan, cerca de 40,000 litros de aceite, no obstante que hubo de perderse una considerable parte de este producto por falta de personal práctico para este beneficio". En el beneficio "se han empleado nueve hombres que han trabajado durante cincuenta y dos días". Se obtuvieron además "una gran cantidad de barbas, existiendo algunas de éstas que alcanzan a 18 pies de largo". Finalmente "se han extraído además algunos huesos del esqueleto, que son una verdadera curiosidad por su gran tamaño". Todos estos productos constituyen lo que el periódico denomina "un valioso cargamento"72.

\section{La Batalla entre Héroes y Monstruos}

Las ballenas son uno de los componentes de las descripciones, el otro corresponde a los balleneros. La mayoría de las referencias registradas tratan a los balleneros como verdaderos héroes que entablan batallas memorables con las monstruosas ballenas. Los pescadores de San Vicente, recién "después de arriesgar su pellejo sus perseguidores durante una semana para dar caza al monstruo marino que burlaba sus pesquisas" "73 pudieron arponearlo. Un ballenero de Tumbes se "halló en [...una] ocasión expuesto a un grave peligro a consecuencia de una colada recia de la ballena, que arrojando sobre la tripulación del bote una fuerte marejada, tiró al jefe de ella al agua i casi hizo ir de pique la embarcación misma" ${ }^{\text {. }}$. En la caleta de Lebu un cetáceo "alcanzó a darle a una chalupa un golpe con la cola, partiéndola en dos pedazos e hiriendo gravemente a uno de los tripulantes, el que hasta ahora está sin poder andar, pues las piernas las tiene contusas" $"$.

Dublé Urrutia relata con pasión estas batallas:

el cetáceo huye en todos sentidos o ataca [...], lanzando enormes chorros de agua i espuma, o dando terribles golpes con la cola. Es cosa frecuente que en este combate se hundan i despedacen los barcos i naufrague la gente que al instante es socorrida por las demás embarcaciones. En lo mejor de esa batalla se presenta de pronto la ocasión propicia para que el monstruo sea trancado ${ }^{76}$.

Los riesgos no solo aparecen en el momento de la batalla, sino también están asociados a los peligros de la navegación. Es lo que le ocurre en el puerto de Lebu a "la chalupa del conocido ballenero Paulino Araya, [ya que] después de pasar la barra y en el momento que se aproximaba al muelle [...] fue dada vuelta por una gran ola que se levantó de repente, que ni la pericia de sus tripulantes bastó para impedir la zozobra"77 (Figura 5).

Pero no solo está el tema de los riesgos físicos y materiales que significa la captura de la ballena, sino que incluso, después de hacerlo, no puedan aprovecharla para su beneficio. Uno de los problemas es que a pesar "de haberle clavado un arpón, no pudieron darle caza" $"$, es decir, la ballena se les escapa. Otro asunto es que "la ballena después de desangrar no ha flotado, como sucede siempre, sobre la superficie del mar" "79, o sea, la ballena se hunde. Finalmente, otra dificultad se presenta

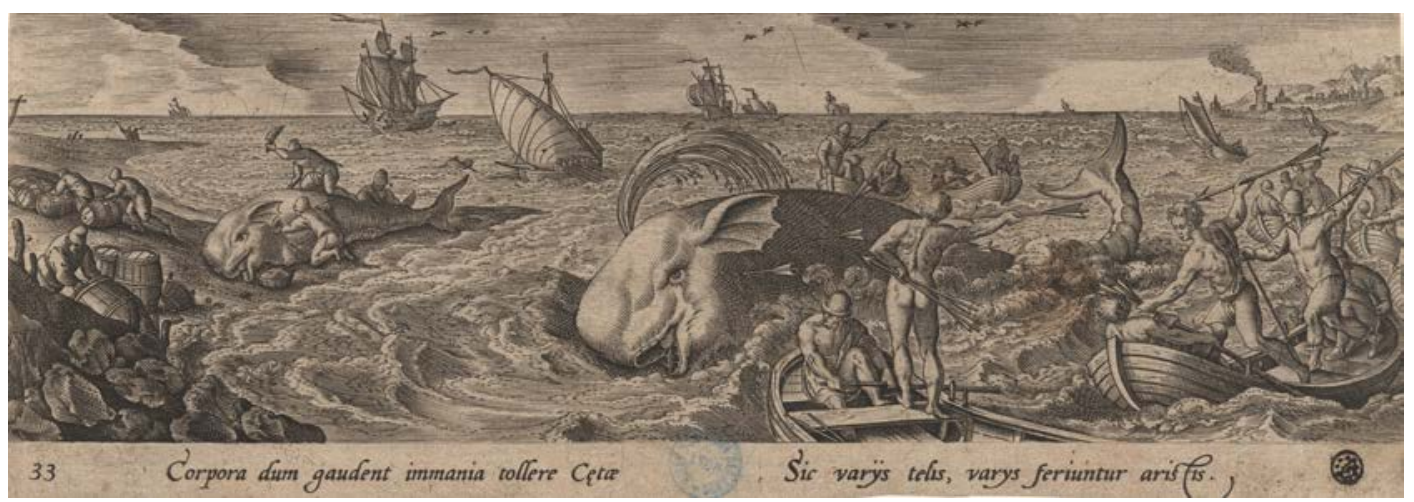

Figura 5. La pesca de la ballena. Hans Bol \& Phillips Galle, Venationis, piscationis et aucupii typi, Amberes, 1582; http://numelyo. bm-lyon.fr/view.php?pid=BML:BML_02EST01000N16GAL003519\&zoom=actif, consultado el 31 de enero de 2019; dominio público.

Whaling. Hans Bol \& Phillips Galle, Venationis, piscationis et aucupii typi, Antwerp, 1582; http://numelyo.bm-lyon.fr/view. php?pid=BML:BML_02EST01000N16GAL003519\&zoom= actif, accessed January 31, 2019; public domain. 
cuando se deja "anclada y fondeada una ballena" en un determinado lugar y no puede ser trasladada a la caleta para su procesamiento "por la braveza del mar"80; además, cuando vuelven a recogerla "al lugar donde habían dejado el cetáceo", no encuentran señales de ella pues "la corriente y el viento se supone que la hayan arrastrado" $"$. De alguna manera, la ballena sigue dando batalla, incluso después de morir.

Las batallas entre humanos y cetáceos son también dignas de contemplarse. Diego Dublé Urrutia (1905a, 1905b) señala que los balleneros de Tumbes, muchas veces, "han dado el espectáculo de la caza de una ballena, dentro de nuestro golfo de Talcahuano i San Vicente; $[\ldots]$ por todas las crestas de los cerros, que dan a la mar, se ven correr las mujeres, los hombres i los niños que han quedado en la caleta". Van a contemplar, "como desde un grandioso palco preparado por la naturaleza, la más imponente de las cazas a que obliga al hombre la lucha por la vida" 82 .

Baldomero Lillo, en su cuento La Ballena, describe con detalles la observación de una de estas "batallas" desde la altura del cerro El Tope de Lebu:

Diez minutos después que el vigía izó en el tope la señal de 'ballena la vista', la Delfina y la Gaviota, con sus remeros por banda, surcaban las aguas de la caleta entre las exclamaciones de la alegre turba de muchachos y muchachas que ascendían los ásperos flancos del monte para presenciar, desde la altura, los incidentes de la liza.

En la cima del empinado cerro flameaba el trapo rojo, teniendo debajo un gallardete blanco para indicar que el cetáceo encontrábase al poniente. $\mathrm{Al}$ pie del mástil, el vigía, un muchacho de rostro moreno curtido por el sol y las brisas marinas, sentado en la menuda hierba, con las manos cruzadas delante de las rodillas, fijaba sus ojos penetrantes en los lejanos e intermitentes surtidores de espuma que la ballena lanzaba sobre la bruñida y esmeraldina superficie del mar. Las chalupas, describiendo una curva para evitar los arrecifes del Guape, deslizábanse a todo remo en la dirección del occidente que les marcaban la banderola y el gallardete (Lillo 1908:s/p).

No es necesario contar el final de la historia.

\section{El Espectáculo de la Ballena}

Pero no solo su cacería sino también la misma ballena es un gran espectáculo (Richter 2015). Un aspecto importante en la relación entre los hombres y las ballenas es la curiosidad que despierta entre las personas la vista de estos cetáceos, vivos o muertos ${ }^{83}$.

En noviembre de 1902 vara en las costas del Estrecho de Magallanes un "colosal" ejemplar de ballena franca y un cachalote "de grandes dimensiones", que serán beneficiados "por una persona entendida en este ramo" "84. Zarpa de Punta Arenas "una goleta [...] conduciendo los elementos necesarios para proceder a beneficiar ${ }^{85}$ una gigantesca ballena y un cachalote que se encuentran varados en esa costa" ${ }^{\text {"86 }}$. Una de estas ballenas, de 52 pies de largo, es remolcada hasta Rio Seco, "donde sus propietarios, señores Braun y Blanchard procederán a su beneficio en la grasería que tienen allí establecida" ". El buque KOSMOS "salió para Río Seco con el señor Curtze y un gran número de personas, para ver el cetáceo. En la mañana de hoy han ido también varias otras personas a caballo" 88 . En resumen, "pasaron de quinientas las personas que a caballo, en carruajes, en bicicletas i aún a pie se dirigieron a ese punto [... dando] inusitada animación a los hoteles, cantinas y aún fogones que no en escaso número existen en el trayecto de la ciudad a Río Seco" ${ }^{" 19}$. La ballena es incluso sacada a remate pero no tuvo postores y "en la grasería de ese lugar será beneficiada por el señor Bermúdez" ${ }^{90}$.

Está también el caso de otra ballena, de 65 pies de largo, varada en Susana Cove y trasladada el 2 de septiembre de 1904 por el capitán T. Steffen hasta la grasería del Sr. Kusanovic en Punta Arenas, donde será beneficiada. Su estado "es perfecto aún y su aprovechamiento será total"'91. Se cuenta que "la cabeza ya ha sido cortada" y de ella "se han obtenido ya cerca de 22 quintales de barbas" 92 . De la misma manera, fue "extraordinario el número de personas que acudieron al sitio donde se halla varada la ballena [...]. A pesar de la gran distancia que hay desde el pueblo hasta ese lugar, las familias, tanto de a pie como en carruajes, se daban cita para estirar un poco las piernas después de un gran tiempo aprisionadas en sus casas con motivo del riguroso invierno". La ballena se encuentra "casi por completo beneficiado y se ha extraído todo el interior para evitar la descomposición"93.

Pero también es "espectacular" la observación de las ballenas capturadas y trasladadas a la playa para procesarlas. Una ballena capturada en Punta de Parra es remolcada a Tumbes "donde quedará para la expectación pública i no será destrozada hasta mañana o pasado" 94 . Un par de días después Tumbes "ofrecía [...] un espectáculo mui animado, habiéndose presentado muchos curiosos para admirar la monstruosa ballena" ${ }^{\circ 5}$. En otro momento se indica que Talcahuano ha estado "de paseos, a Tumbes a ver la ballena y a San Vicente a comer apancoras [de modo que] Tumbes fue visitado por la mitad de Talcahuano y San Vicente por la otra mitad"96. Incluso, algunos años después, los pescadores de Tumbes ponen una de sus ballenas cazadas "en exhibición a 50 centavos la entrada" ${ }^{97}$.

Las noticias sobre la curiosidad que despiertan las ballenas se repiten incesantemente en el registro. La pesca de un par de ballenas logra que nuevamente las caletas de Tumbes y San Vicente se llenen "con los 
novedosos que fueron a ver estos horribles monstruos. La emigración de viejos, viejas, niñas, etc., duró todo el día" "98. O bien que "numerosas personas se han dirigido a la bahía de San Vicente hoy y ayer a ver la ballena que los pescadores de allí pescaron en días pasados y que ayer solamente ha sido traída a tierra" 99 (Figura 6).

Otra ballena trasladada a San Vicente provoca que "un buen número de personas se prepara mañana para ir a verla. Recomendamos a los aficionados a esta clase de excursiones aprovechen la ocasión que se les presenta" 100 . En esta oportunidad se asegura que "mucho tiempo hacía que San Vicente no había sido visitado por tanta gente, como ayer temprano principió a llegar con el objeto de ver la ballena de que dimos cuenta en nuestra correspondencia de ayer" "101. Luego que pescadores de San Vicente "trancaran" una ballena frente a Hualpén y la llevaran a la playa de San Vicente, "muchos curiosos han ido a aquel lugar a admirar ese monstruo de los mares"102, logrando formar "una concurrencia de cerca de cinco mil personas" 103 .

La curiosidad se mantendrá en el tiempo. El 6 de marzo de 1907 un grupo de pescadores de San Vicente "fisgaron [...] una ballena que remolcaron a la caleta", provocando que "infinidad de curiosos hayan concurrido a verla" ${ }^{104}$. Lo más notable es que este evento fue fotografiado y las imágenes publicadas ${ }^{105}$.

La curiosidad no se relaciona solo con la contemplación de animales muertos. Tenemos varios datos asociados a la observación de animales vivos, en aquellos lugares donde dicho espectáculo resulta posible.
PuntaArenas es un buen lugar desde donde observar ballenas. En noviembre de 1901 aparecen "sobre las olas i casi al costado del vapor, dos enormes ballenas, tal vez las más grandes que hemos tenido oportunidad de ver, las que volvieron a sumergirse majestuosamente en el mar, continuando su viaje en dirección a los helados mares del sur i causando entre los pasajeros el asombro i admiración que siempre despierta el espectáculo de este enorme cetáceo, verdadero rey de los mares" ${ }^{106}$. Un mes después, se divisa "una gran ballena muy cercana a los pontones, donde estuvo navegando algún tiempo; después se alejó en dirección al sur"107.

Debemos notar que lo más visible y notorio del cetáceo es su "espauto" [del inglés spout] ${ }^{108}$, el característico "chorro de agua" que lanzan cuando respiran: se puede observar "paseando por la bahía, cuatro o cinco grandes ballenas, levantando enormes columnas de agua y atrayendo a los muelles numerosa concurrencia que las contemplaba. Muchas veces vinieron tan cerca de tierra, que parecía imposible no varasen en ella"109; "se puede observar desde hace dos días un espectáculo no muy corriente en el estrecho: un gran número de ballenas que arrojan a cada instante sus formidables columnas de agua en la bahía" ${ }^{110}$; también "se ha visto en las aguas de esta bahía una hermosa ballena, admirándose la elevación de los chorros de agua que despedía" "111. Es interesante subrayar que este espectáculo causa "la entretención de mucha gente que contempla desde tierra las evoluciones marinas de estos colosos"112

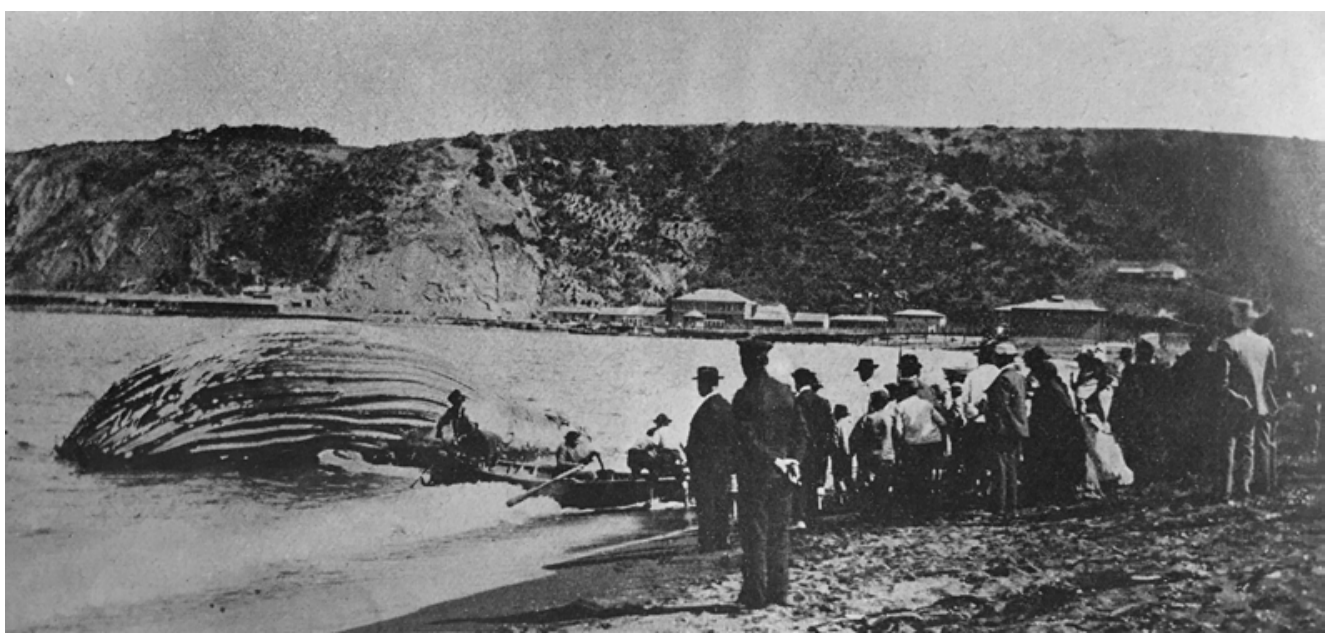

Figura 6. Procesamiento de una ballena en San Vicente, Chile, 1907. En Sucesos No 237, 21 de marzo de 1907 [Hemeroteca Biblioteca Nacional].

Processing of a whale in San Vicente, Chile, 1907. In Sucesos, $N^{\circ}$ 237, March 21, 1907 [Hemeroteca Biblioteca Nacional]. 


\section{Colofón}

Los recortes nos indican que lo monstruoso en la ballena está asociado, principalmente, con su enorme tamaño y su gran bravura. Algunos ven belleza en la misma monstruosidad. La ballena es "la reina de los mares". Es interesante observar que los japoneses usan dos términos para nombrar la ballena, kujira, que quiere decir "pez grande", e isana, uno de cuyos significados es "pez bravo" (Kato 2007:290). Lo monstruoso no es justificación ni tampoco evita la confrontación del hombre con la ballena. El aceite, la carne, las barbas, dientes y huesos de los cetáceos son necesarios para la supervivencia de los humanos. Esta necesidad los lleva a enfrentarse en el mar y sostener épicas batallas, de la que no es seguro el vencedor, la ballena o el ballenero. Las batallas generan un discurso en el que el ballenero adquiere características de héroe. En palabras de Dublé Urrutia (1905a, 1905b), hablando de los balleneros de Tumbes, "las lanzas y los arpones esperan afirmadas en las paredes la hora en que algún ojo avizor descubra en el horizonte el lomo resplandeciente del monstruo o sus blancos torbellinos de agua. Bajo ramadas especiales o a pleno sol esperan las chalupas de guerra el momento de salir a esas largas cacerías que, en ocasiones, duran 5 o 6 días, y que con frecuencia se extienden hasta la isla Santa María, la Mocha y Ancud"113.

La ballena y los productos que se obtienen de ella son una mercancía valiosa. No siempre la cosecha es la esperada, a veces, las ballenas son pequeñas, de modo que, "el producido será muy poco; pero, en fin, habrá que conformarse; $[\ldots]$ de todas maneras, felicitamos a nuestros pescadores, deseándoles que para otra ocasión anden con más suerte que esta vez"114. La ballena es un recurso, pero mantiene algunas de sus características de "monstruo". Las personas capaces de dominarlos, los balleneros, son construidos como verdaderos "héroes", involucrados en una lucha cuerpo a cuerpo con "el monstruo", que los supera muchas veces en tamaño y fuerza (Figura 7).

La batalla entre los hombres y los cetáceos es un espectáculo, pero no se encuentra solo en la lucha sino también en la simple observación de la ballena, del cuerpo "monstruoso" de la ballena muerta, varada o cazada, depositada en alguna playa, y de la ballena viva, resoplando y surcando los mares frente a costas pobladas por multitudes de curiosos.

El surgimiento y expansión global de la caza moderna de ballenas contribuye a reducir en el imaginario de la época la importancia de ciertas cualidades en los balleneros, y comienza a predominar la naturaleza tecnológica de las armas utilizadas para cazarlas. El cañón arponero representa, sin duda, la eficiencia tecnológica, un poco en desmedro de la pericia humana (aunque obviamente se la necesite para usarlo de buena manera). La caza de ballenas pasa a ser "un acto de barbarismo", no tradicional, sino "anacrónico", y los seres humanos pasan a ser considerados los verdaderos "monstruos", y las ballenas, sus "víctimas". Sin embargo, las personas siguen visitando a sus víctimas.

La observación de ballenas se ha constituido en una gran industria (Hoyt y Parsons 2014). Las ballenas siguen portando esa naturaleza "monstruosa" que las hace tan atractivas para los seres humanos, quienes las siguen por todas partes del mundo, en algún momento fue para matarlas, y ahora sólo quieren "verlas" y/o "estudiarlas" (Quiroz y Carreño 2017:52).

Las ballenas ya no son un recurso para cazar sino un poderoso recurso para contemplar y también un significativo símbolo de los esfuerzos conservacionistas por proteger el ambiente de los "extravíos" humanos. Su naturaleza aún sigue siendo múltiple y contradictoria.

Agradecimientos: Este trabajo ha sido escrito en el marco del Proyecto Fondecyt Regular 1170318, que ha financiado nuestras incursiones en bibliotecas, archivos y museos, tanto del país como del extranjero. Quiero agradecer en forma muy especial a los estudiantes de antropología de la Universidad Academia de Humanismo Cristiano de Santiago de Chile, Estefanía Díaz, Margarita Berríos, Nicolás Valenzuela y Camila Erazo, quiénes han participado en esta búsqueda obsesiva de noticias sobre ballenas en los periódicos chilenos. También agradezco a Samantha Miranda ex alumna de antropología de la Universidad de Chile, por su exhaustiva búsqueda de datos en los diarios penquistas. Finalmente mi reconocimiento a los revisores externos pues sus comentarios permitieron mejorar de manera sustantiva el texto. 


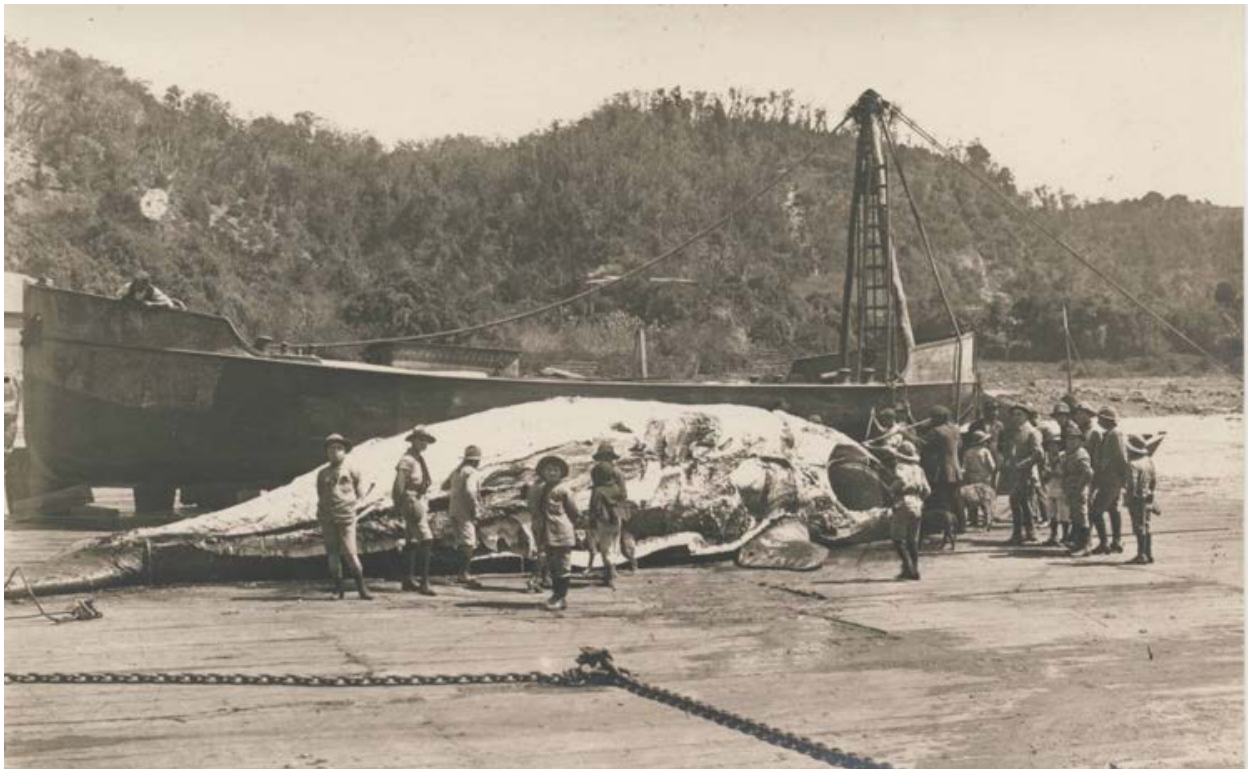

Figura 7. Un grupo de Boy scout de visita en la planta ballenera de San Carlos de Corral, ca. 1930 [Gentileza de Erik Evensen, Tønsberg, Noruega].

Boy scout group visiting the whaling station of San Carlos de Corral, ca. 1930 [Courtesy of Erik Evensen, Tonsberg, Norway].

\section{Referencias Citadas}

Anónimo 1832. Les mille et une nuits. Contes Árabes. Tomo II Traducida al francés por M. Galland. Imprimerie de Cassimir, Paris.

Anónimo 1917. The King's Mirror. Traducido al inglés por L.M Larson. The American-Scandinavian Foundation/Oxford University Press, New York.

Anónimo 1921. The Old English Physiologus. Traducido al inglés por A.S. Cook y J.H. Pitman. Yale University Press, New Haven.

Ballester, B. 2018. El Médano rock art style: Izcuña paintings and the marine hunter-gatherers of the Atacama Desert. Antiquity 92 (361):132-148

Bernaert, M.B.F. 1829. Notice sur la Baleine échouée près d'Ostende, le 5 novembre 1827. Le Normant Fils, Paris.

Branch, G.M., M.L, Branch, C.L Griffiths y L.E Beckley 2010. Two Oceans: A guide to the Marine Life of Southern Africa. David Phillips Publisher, Cape Town

Braun, J., M. Braun, I. Briones, J. Díaz, R. Luders y G. Wagner 2000. Economía Chilena 1810-1995: Estadísticas Históricas Documento de Trabajo $\mathrm{N}^{\circ} 187$. Instituto de Economía, Pontificia Universidad Católica de Chile, Santiago.

Brito, C. 2018. Beauties and beasts: whales in Portugal, from Early-Modern monsters to today's flagship species. Arcadia $21: \mathrm{s} / \mathrm{p}$.

Brito, C., N. Vieira y J. G. Freitas 2019. The wonder whale: a commodity, a monster, a show and an icon. Anthropozoologica $54(3): 13-27$

Cardona Ramírez, H. 2005. El Libro de Jonás, perspectivas introductorias. Cuestiones Teológicas 32 (77):189-202.
Castillo, L. 1906. La Pesca de la Ballena en la isla Santa María. Cervantes, Santiago.

Castillo, L. 1907. La reglamentación de la caza de ballenas Anales Agronómicos II (1-2):157-165.

Chapman, A. 2012. Yaganes del Cabo de Hornos. Encuentros con los europeos antes y después de Darwin. Pehuén, Santiago.

Clarke R. 1965. Southern right whale on the coast of Chile Norsk Hvalfangst-Tidende 54 (6):121-128.

Coleman, J.L. 1995. The American whale oil industry: A look back to the future of the American petroleum industry? Non Renewable Resources 4 (3):273-288.

Collodi, C. 1983. Le avventure di Pinocchio. Storia di un Burattino. Fondazione Nazionale Carlo Collodi, Pescia.

Corbella, D. 1991. 'El viaje de San Brandán': una aventura de iniciación. Filología Románica 8:133-147.

Cuevas, Y. 2011. Representaciones sociales en la prensa aportaciones teóricas y metodológicas. Sinéctica 36:s/p. http://www.sinectica.iteso.mx/index.php?cur=36\&art=36_08) (19 febrero 2019)

Dublé Urrutia, D. 1905a. Tumbes (IV). La pesca de la ballena. José Olivares i las ballenas. El Sur (Concepción), 5 de febrero de 1905:4.

Dublé Urrutia, D. 1905b. Tumbes (V). La caza de la ballena. $E l$ Sur (Concepción), 7 de febrero de 1905:1-2.

Esser-Miles, C. 2014. 'King of the children of pride': Symbolism, phisicality, and the old english whale. En The Maritime World 
of the Anglo-Saxons, editado por S.S. Klein, W. Schippes y S. Lewis-Simpson, pp. 275-301. ACMRS, Tempe.

González de Agüeros, P. 1791. Descripción Historial de la Provincia y Archipiélago de Chiloé, en el Reyno de Chile. Imprenta de Don Benito Cano, Madrid.

González de Nájera, A. 1866. Desengaño y Reparo de la Guerra del Reino de Chile. Imprenta de la viuda de Calero, Madrid.

Grize, J.B. 1996. Logique naturelle et communications. Presses Universitaires de France, Paris.

Gusinde, M. 1951. Hombres Primitivos en la Tierra del Fuego: (de Investigador a Compañero de Tribu). Escuela de Estudios Hispano-Americanos de Sevilla, Sevilla.

Gutiérrez, S. 2006. Las representaciones sociales desde una perspectiva discursiva. Versión 17:231-256.

Hoyt, E. y C. Parsons 2014. The whale-watching industry: historical development. En Whale-Watching: Sustainable Tourism and Ecological Management, editado por J. Higham, L. Bejder y R. Williams, pp. 57-70. Cambridge University Press, Cambridge.

Kalland, A. 2009. Unveiling the Whale. Discourses on Whales and Whaling. Berghan, New York.

Kato, K. 2007. Prayers for the whales: spirituality and ethics of a former whaling community-intangible cultural heritage for sustainability. International Journal of Cultural Property 14:283-313.

Latour, B. 2007. Nunca fuimos modernos. Ensayo de antropología simétrica. Siglo XXI, Buenos Aires.

Lawrence, T.B. y N. Philips 2004. From Moby Dick to Free Willy: macro-cultural discourse and institutional entrepreneurship in emerging institutional fields. Organizations 11:689-711.

Lillo, B. 1908. La Ballena. Zig Zag (Santiago), 199 (13 de diciembre):s/p.

Massa Sanguinetti, C. 1858. Diccionario Jurídico-Administrativo o Compilación General de Leyes, Decretos y Reales Órdenes Dictados en todos los ramos de la Administración Pública. Imprenta de la Revista de Legislación y Jurisprudencia, Madrid.

Miéville, D. 1986. Prelude a l'analyse du descriptif. Cahier de Logique 52:119-146.

Miller, R. J. 2000. Exercising cultural self-determination: The makah indian tribe goes whaling. American Indian Law Review 25 (2):165-273.

Molina, J.I. 1788. Compendio de la Historia Geográfica, Natural y Civil del Reino de Chile. Tomo I. Imprenta de Sancha, Madrid.

O'Connor, S., R. Campbell, H. Cortez y T. Knowles 2010. Whale-Watching Worldwide: Tourism numbers, expenditures and expanding economic benefits. International Fund of Animal Welfare, Yarmouth.

Oslund, K. 2004. Protecting fat mammals or carnivorous humans? Towards an environmental history of whales. Historical Social Research 29 (3):63-81.

Ovalle, A. 1969 [1646]. Histórica Relación del Reino de Chile. Editorial Universitaria, Santiago.

Parnwell, M. 2014. Regional resonances: vietnamese whale worship in comparative perspective. En The Great Diversity:
Trajectories of Asian Development, editado por C. Brautaset y C. Dent, pp. 83-101. Wageningen Academics Publishers, Wageningen.

Pastene, L.A. y D. Quiroz 2010. Outline of the history of whaling in Chile. En Human Culture from the Perspective of Traditional Maritime Communities, editado por International Center for Folk Culture Studies, pp. 73-98. Kanagawa Shimbun Press, Kanagawa.

Pitta, S. da R. 1730. História da América Portugueza, desde o Anno de Mil e Quinhentos do seu Descobrimento, até o de Mil e Setecentos e Vinte e Quatro. Officina de Joseph Antonio da Silva, Lisboa.

Poeppig, E. 1960. Un Testigo en la Alborada de Chile (18261829). Zig-Zag, Santiago.

Quiroz, D. 2011. La flota de la Sociedad Ballenera de Magallanes: historias y operaciones en los mares australes (1905-1916). Magallania 39 (1):33-58.

Quiroz, D. 2016. Excursiones etnográficas entre los pescadores de ballenas de Tumbes y la isla Santa María, Chile, a comienzos del siglo XX. Antropologías del Sur 5:103-123.

Quiroz, D., G. Carreño y P. de la Fuente 2016. El procesamiento de ballenas varadas en las costas de la Patagonia Occidental [a propósito de un grabado de mediados del siglo XIX]. Magallania 44(1):57-72.

Quiroz, D. y G. Carreño 2017. Narrativas etnográficas sobre ballenas y balleneros en las costas de Chile. Antípoda 28:31-51.

Quiroz, D. y M. Mayorga 2018. Un experimento temprano de caza moderna de ballenas en Magallanes: el vapor Magallanes de la Braun \& Blanchard y el capitán Andresen. Magallania 46 (2):25-46.

Quiroz, D. y L. Pastene 2014. Norwegian whaling in Chile in the 20th century and it influences on Chilean local communities. En Whaling \& History IV, editado por J.-E. Ringstad, pp. 6170. Vestfold Museene IKS, Sandefjord.

Richter, V. 2016. 'Where things meet in the world between sea and land': Human-Whale encounters in littoral space. En The Beach in Anglophone Literatures and Cultures:Reading Littoral Space, editado por U. Kluwick y V. Richter, pp. 155-173. Routledge, Londres.

Rosales, D. de 1877. Historia General del Reyno de Chile. Flandes Indiano. Imprenta de El Mercurio: Valparaíso.

Singleton, B.E. y R. Lidskog 2018. Science, red in tooth and claw: Whaling, purity, pollution and institutions in marine mammal scientists' boundary work. Environment and Planning E: Nature and Space 1 (12):165-185.

Swensen, E.F. 2014. Foraging in the Yamana-English Dictionary. Explorin $g$ Ethnographical Sources of Tierra del Fuego and a Discussion of their Relevance to the Archaeological Record in the Beagle Channel. Norwegian University of Science and Technology, Trondheim.

Szabo, V.E. 2005. 'Bad to the bone'? The unnatural history of monstrous medieval whales. The Heroic Age. A Journal of Early Medieval Northwestern Europe 8:s/p. (www.heroicage. org/issues/8/szabo.html) (1 marzo 2018).

Szabo, V.E. 2008. Monstrous Fishes and the Mead-Dark Sea: Whaling in the Medieval North Atlantic. Brill Academic Publishers, Leiden.

Teobaldus, B. 1928. Physiologus. A Metrical Bestiary of Twelve Chapter by Bishop Teobaldus. Traducido por A. W. Rendell. John \& Edward Bumpus Ltd., Londres. 
Vieira, N. 2018. A comparative approach to historical whaling techniques: transfer of knowledge in the 17th century from the Biscay to Brazil. En Cross-cultural exchange and the circulation of knowledge in the First Global Age, editado por A. Polónia, F Bracht, G.C. Conceição y M. Palma, pp. 125-143. Afrontamento, Porto.

\section{Fuentes Primarias}

[Manuscritos Censales de Talcahuano]. Archivo Histórico Nacional, Fondo Intendencia de Concepción, volumen 421.

\section{Periódicos y Revistas}

Boletín de las Leyes i de las Órdenes i Decretos del Gobierno (Santiago), 1863.
El Correo del Sur (Concepción), 1852-1865.

La Tarántula (Concepción) 1862-1871.

La Revista del Sur (Concepción), 1871-1886.

El Sur (Concepción), 1885-1905.

El Lebu (Lebu), 1897-1905.

El Araucano (Lebu), 1882-1898.

El Magallanes (Punta Arenas), 1894-1905.

El Comercio (Punta Arenas), 1900-1905.

Sucesos (Santiago), 1907.

\section{Notas}

${ }^{1}$ Es interesante considerar que en la versión de 1940 de Walt Disney de Pinocho (1940), el "pesce-cane" es una ballena conocida con el nombre de Monstro.

${ }^{2}$ Coselete es el nombre que se le daba en los siglos XVI y XVII a una coraza ligera, generalmente de cuero, que usaban ciertos soldados de infantería.

${ }^{3}$ [Manuscritos censales de Talcahuano]. Archivo Histórico Nacional, Fondo Intendencia de Concepción, volumen 421.

${ }^{4}$ Estos permisos eran necesarios según una disposición legal que imponía restricciones al desarrollo de la industria ballenera con el fin de impedir el contrabando [Reglas a que deben sujetarse los pescadores de ballena en la provincia de Concepción. Decreto Supremo del 29 de mayo de 1863 del Ministerio de Hacienda. Boletín de las Leyes i de las ordenes i decretos del gobierno. Santiago: Nacional. XXXI (5):115$116]$.

${ }^{5}$ La Tarántula (Concepción), 1 de marzo de 1869.

${ }^{6}$ Buscamos sistemáticamente en los diarios El Correo del Sur [1852-1865], La Tarántula [1862-1871], La Revista del Sur [1871-1886] y El Sur [1885-1905], de Concepción; El Lebu [1897-1905] y El Araucano [1882-1898] de Lebu; El Magallanes [1894-1905] y El Comercio [1900-1905], de Punta Arenas. Nuestro interés era abarcar, al menos, un período de medio siglo [1852-1905]. Fueron consultados todos los números de El Correo del Sur, La Tarántula, La Revista del Sur y El Araucano que se encuentran en la Sección Periódicos de la Biblioteca Nacional. Los diarios El Sur, El Lebu, El Comercio y El Magallanes siguieron publicándose después de 1905, pero estos ejemplares no fueron revisados. ${ }^{7}$ Incluimos excepcionalmente una noticia que habla de un accidente de una chalupa ballenera mientras realizaba una actividad distinta a la caza, como una forma de ilustrar los peligros de la navegación en la costa araucana.

${ }^{8}$ Diego Dublé Urrutia publica, en seis entregas, un largo reportaje sobre la caleta de Tumbes en el diario El Sur de Concepción, en el que incluye diversos datos sobre la pesca local de ballenas en los ejemplares de los días 5 y 7 de febrero de 1905 (Dublé Urrutia 1905a, 1905b).

${ }^{9}$ El Correo del Sur (Concepción), 4 de diciembre de 1862.

${ }^{10} \mathrm{El}$ Correo del Sur (Concepción), 31 de octubre de 1863.

${ }^{11}$ La Tarántula (Concepción), 10 de septiembre de 1864.

${ }^{12}$ El Sur (Concepción), 7 de febrero de 1905.

${ }^{13} \mathrm{El}$ Correo del Sur (Concepción), 4 de diciembre de 1862.

${ }^{14}$ La Revista del Sur (Concepción), 7 de marzo de 1878

${ }^{15}$ El Sur (Concepción) 9 de diciembre de 1896.

${ }^{16} \mathrm{El}$ Correo del Sur (Concepción), 31 de octubre de 1863.

${ }^{17}$ La Tarántula (Concepción), 7 de noviembre de 1863, 10 de septiembre de 1864. Curiosamente, en otro recorte, se habla de una ballena "no muy hermosa", no sabemos si se refiere a ese ejemplar particular o a todas las ballenas [La Revista del Sur (Concepción), 7 de diciembre de 1875].

${ }^{18}$ El Correo del Sur (Concepción), 4 de diciembre de 1862.

${ }^{19}$ La Tarántula (Concepción), 5 de septiembre de 1863.

${ }^{20} \mathrm{El}$ Correo del Sur (Concepción), 29 de octubre de 1863.

${ }^{21}$ El Correo del Sur (Concepción), 31 de octubre de 1863.

${ }^{22}$ El Correo del Sur (Concepción), 29 de octubre de 1863.

${ }^{23}$ La vara de Castilla equivale a $0,836 \mathrm{~m}$. Real Orden de 9 de diciembre de 1852, por la que se determinan las tablas de correspondencia recíproca entre las pesas y medidas métricas y las actualmente en uso (Massa Sanguinetti 1858: 643-656). La ballena en referencia medía, entonces, un poco más de 27 metros de largo, y por el tamaño debería corresponder a una ballena azul o de aleta.

${ }^{24} \mathrm{El}$ Correo del Sur (Concepción), 31 de octubre de 1863.

${ }^{25}$ La Revista del Sur (Concepción), 7 de marzo de 1878.

${ }^{26} \mathrm{La}$ Revista del Sur (Concepción), 18 de febrero de 1885.

${ }^{27}$ El Sur (Concepción), 8 de mayo de 1894.

${ }^{28}$ El Sur (Concepción), 9 de diciembre de 1896.

${ }^{29}$ El Sur (Concepción), 15 de septiembre de 1898.

${ }^{30} \mathrm{El}$ Sur (Concepción), 29 de octubre de 1898.

${ }^{31}$ El Sur (Concepción), 22 de marzo de 1888

${ }^{32}$ El Araucano (Lebu), 17 de agosto de 1890.

${ }^{33}$ El Araucano (Lebu), 6 de abril de 1890.

${ }^{34}$ El Araucano (Lebu), 21 de septiembre de 1890.

${ }^{35} \mathrm{El}$ Araucano (Lebu), 14 de diciembre de 1890.

${ }^{36}$ El Comercio (Punta Arenas), 24 de noviembre de 1902

${ }^{37}$ El Magallanes (Punta Arenas), 26 de noviembre de 1902.

${ }^{38} \mathrm{El}$ Comercio (Punta Arenas), 15 de noviembre de 1904

${ }^{39} \mathrm{El}$ Sur (Concepción), 28 de enero de 1905.

${ }^{40}$ El Sur (Concepción), 29 de octubre de 1898.

${ }^{41}$ El Correo del Sur (Concepción), 4 de diciembre de 1862.

${ }^{42}$ La Tarántula (Concepción), 7 de noviembre de 1863.

${ }^{43}$ El Correo del Sur (Concepción), 31 de octubre de 1863.

${ }^{44}$ La Revista del Sur (Concepción), 18 de febrero de 1885.

${ }^{45} \mathrm{El}$ Sur (Concepción), 9 de diciembre de 1896.

${ }^{46}$ El Sur (Concepción), 6 de enero de 1898.

${ }^{47}$ El Sur (Concepción), 15 de septiembre de 1898.

${ }^{48}$ El Sur (Concepción), 29 de octubre de 1898.

${ }^{49}$ Como un barril son 42 galones, 30 barriles serían 1.260 galones.

${ }^{50}$ En este caso seguimos la aseveración del diario que señala que cada barril es de 40 galones y no la equivalencia normal de 42 galones.

${ }^{51}$ El Sur (Concepción), 15 de septiembre de 1898.

${ }^{52}$ El Sur (Concepción), 29 de octubre de 1898.

${ }^{53}$ El Sur (Concepción), 15 de septiembre de 1898.

${ }^{54}$ El Sur (Concepción), 29 de octubre de 1898.

${ }^{55}$ El Araucano (Lebu), 17 de agosto de 1890 
${ }^{56}$ El Araucano (Lebu), 21 de septiembre de 1890

${ }^{57} \mathrm{El}$ Araucano (Lebu), 14 de diciembre de 1890

${ }^{58}$ El Correo del Sur (Concepción), 31 de octubre de 1863.

${ }^{59} \mathrm{El}$ Sur (Concepción), 15 de septiembre de 1898.

${ }^{60} \mathrm{El}$ Sur (Concepción), 15 de septiembre de 1898, 29 de octubre de 1898.

${ }^{61}$ El Sur (Concepción), 15 de septiembre de 1898.

${ }^{62}$ El Sur (Concepción), 29 de octubre de 1898.

${ }^{63}$ El Sur (Concepción), 29 de octubre de 1898.

${ }^{64}$ Un quintal español equivale a unas 100 libras castellanas o $46,01 \mathrm{~kg}$. El quintal estadounidense equivale también a 100 libras, pero corresponde a $45,36 \mathrm{~kg}$.

${ }^{65}$ El Sur (Concepción), 15 de septiembre de 1898

${ }^{66}$ El Sur (Concepción), 29 de octubre de 1898.

${ }^{67} \mathrm{El}$ Sur (Concepción), 29 de octubre de 1898.

${ }^{68}$ El Sur (Concepción), 29 de octubre de 1896.

${ }^{69}$ Hemos usado la tabla de conversión que aparece en https:// westegg.com/inflation/infl.cgi.

${ }^{70}$ Ver https://si3.bcentral.cl/Indicadoressiete/secure/ Indicadoresdiarios.aspx.

${ }^{71}$ El Comercio (Punta Arenas), 10 de septiembre de 1904.

${ }^{72}$ El Comercio (Punta Arenas), 15 de noviembre de 1904

${ }^{73} \mathrm{El}$ Correo del Sur (Concepción), 4 de diciembre de 1862.

${ }^{74} \mathrm{El}$ Correo del Sur (Concepción), 31 de octubre de 1863.

${ }^{75} \mathrm{El}$ Araucano (Lebu), 14 de diciembre de 1890.

${ }^{76}$ El Sur (Concepción), 7 de febrero de 1905.

${ }^{77} \mathrm{El}$ Araucano (Lebu), 20 de julio de 1890

${ }^{78}$ La Tarántula (Concepción), 10 de septiembre de 1864.

${ }^{79}$ El Correo del Sur (Concepción), 4 de diciembre de 1862.

${ }^{80} \mathrm{El}$ Araucano (Lebu), 18 de julio de 1885

${ }^{81}$ El Araucano (Lebu), 29 de septiembre de 1889.

${ }^{82}$ El Sur (Concepción), 5 de febrero de 1905.

${ }^{83}$ La Revista del Sur (Concepción), 7 de diciembre de 1875.

${ }^{84} \mathrm{El}$ Comercio (Punta Arenas), 24 de noviembre de 1902

${ }^{85}$ Beneficiar es el nombre que se le da en las costas de
Concepción y Arauco al proceso de recuperación del tocino de la ballena y su transformación en aceite

${ }^{86}$ El Magallanes (Punta Arenas), 26 de noviembre de 1902

${ }^{87}$ El Magallanes (Punta Arenas), 24 de diciembre de 1902

${ }^{88}$ El Comercio (Punta Arenas), 24 de diciembre de 1902

${ }^{89}$ El Magallanes (Punta Arenas), 25 de diciembre de 1902

${ }^{90} \mathrm{El}$ Comercio (Punta Arenas), 26 de diciembre de 1902

${ }^{91}$ El Comercio (Punta Arenas), 3 de septiembre de 1904

${ }^{92}$ El Magallanes (Punta Arenas), 3 de septiembre de 1904

${ }^{93}$ El Magallanes (Punta Arenas), 5 de septiembre de 1904

${ }^{94} \mathrm{El}$ Correo del Sur (Concepción), 29 de octubre de 1863.

${ }^{95} \mathrm{El}$ Correo del Sur (Concepción), 31 de octubre de 1863.

${ }^{96}$ La Tarántula (Concepción), 2 de noviembre de 1864.

${ }^{97}$ La Revista del Sur (Concepción), 13 de febrero de 1874.

${ }^{98}$ La Revista del Sur (Concepción), 7 de marzo de 1878.

${ }^{99}$ La Revista del Sur (Concepción), 19 de febrero de 1885.

${ }^{100} \mathrm{El}$ Sur (Concepción), 20 de marzo de 1888

${ }^{101}$ El Sur (Concepción), 22 de marzo de 1888

${ }^{102}$ El Sur (Concepción), 9 de diciembre de 1896.

${ }^{103} \mathrm{El}$ Sur (Concepción), 10 de diciembre de 1896.

${ }^{104} \mathrm{El}$ Sur (Concepción), 7 de marzo de 1907.

${ }^{105}$ Sucesos (Santiago), N ${ }^{\circ} 237,21$ de marzo de 1907.

${ }^{106}$ El Magallanes (Punta Arenas), $1^{\circ}$ de noviembre de 1901

${ }^{107}$ El Magallanes (Punta Arenas), 23 de diciembre de 1901

${ }^{108}$ Todas las ballenas tienen que respirar en la superficie y cuando exhalan producen un "chorro" de aire húmedo y cálido proveniente de orificios en la parte superior de sus cabezas que se condensa al salir al exterior.

${ }^{109}$ El Magallanes (Punta Arenas), 4 de enero de 1902.

${ }^{110}$ El Magallanes (Punta Arenas), 17 de diciembre de 1902.

${ }^{111}$ El Magallanes (Punta Arenas), 23 de febrero de 1904

${ }^{112}$ El Magallanes (Punta Arenas), 17 de diciembre de 1902.

${ }^{113}$ El Sur (Concepción), 28 de enero de 1905.

${ }^{114} \mathrm{El}$ Araucano (Lebu), 6 de abril de 1890. 
